NBER WORKING PAPER SERIES

FINANCIAL FRICTIONS AND THE PERSISTENCE OF HISTORY: A QUANTITATIVE EXPLORATION

\author{
Francisco J. Buera \\ Yongseok Shin \\ Working Paper 16400 \\ http://www.nber.org/papers/w16400
}

\author{
NATIONAL BUREAU OF ECONOMIC RESEARCH \\ 1050 Massachusetts Avenue \\ Cambridge, MA 02138 \\ September 2010
}

The authors gratefully acknowledge the support of the National Science Foundation under grant number SES-0820318. The views expressed herein are those of the authors and do not necessarily reflect the views of the National Bureau of Economic Research.

NBER working papers are circulated for discussion and comment purposes. They have not been peerreviewed or been subject to the review by the NBER Board of Directors that accompanies official NBER publications.

(C) 2010 by Francisco J. Buera and Yongseok Shin. All rights reserved. Short sections of text, not to exceed two paragraphs, may be quoted without explicit permission provided that full credit, including (C) notice, is given to the source. 
Financial Frictions and the Persistence of History: A Quantitative Exploration

Francisco J. Buera and Yongseok Shin

NBER Working Paper No. 16400

September 2010

JEL No. E21,E22,E44,O11,O16,O25,O4,O53

\begin{abstract}
We quantify the role of financial frictions and the initial misallocation of resources in explaining development dynamics. Following a reform that triggers efficient reallocation of resources, our model economy with financial frictions converges slowly to the new steady state-it takes twice as long to cover half the distance to the steady state as the neoclassical growth model. Investment rates and total factor productivity start out low and rise over time. These model dynamics are endogenously determined by the extent of initial resource misallocation and the degree of financial frictions. We present data from post-war miracle economies on the evolution of macro aggregates, factor reallocation, and establishment size distribution, which support the aggregate and micro-level implications of our theory.
\end{abstract}

Francisco J. Buera

Department of Economics

University of California, Los Angeles

8283 Bunche Hall Office 8357

Mail Stop: 147703

Los Angeles, CA 90095

and NBER

fjbuera@econ.ucla.edu

Yongseok Shin

Department of Economics

Washington University in St. Louis

1 Brookings Dr

Saint Louis, MO 63130

yshin@wustl.edu 
The development dynamics of post-war miracle economies are characterized by a sustained growth of per-capita income and total factor productivity (TFP), and investment rates that rose over time.

These growth facts are not explained by standard growth models. In the neoclassical model, such transitions can only be understood as a transition from an initial state with low capital stock to a steady state with high capital stock. This transition is characterized by a fast convergence - even the economic miracles seem three times slower when compared to a conventionally-calibrated neoclassical model - and investment rates that monotonically decrease throughout. Furthermore, for a neoclassical model, TFP is an exogenously given input, and hence it offers no insight into TFP dynamics.

The objective of our paper is to provide a theory of TFP dynamics and build upon it a quantitative framework for understanding the process of economic development.

To this end, we incorporate into the standard growth model two important features of the economic miracles. First, their growth accelerations followed large and broad economic reforms that reduced distortions in the economy and led to reallocation of resources across sectors and plants, as we empirically establish in this paper. Second, the miracle economies' financial markets remained largely underdeveloped until the latter stages of their economic transitions, as evidenced by their low ratios of external finance to gross domestic product (GDP).

In our model, transition dynamics are endogenously determined by the extent of resource misallocation in the pre-reform economy and the degree of imperfections in financial markets. Our model generates persistent growth in per-capita output and TFP, and investment rates that start low but rise over time. In particular, its transition speed is half that of the conventionally-calibrated neoclassical model.

To be more specific, we incorporate individual-specific technology - entrepreneurshipand financial frictions into an otherwise-standard neoclassical model. In our model, individuals differ in their entrepreneurial productivity and choose each period whether to be an entrepreneur and operate his technology or to supply labor for wage. This occupation choice allows for endogenous entry into and exit from the production sector, which are important channels of resource reallocation. We model financial frictions in the form of collateral constraints arising from imperfect enforceability of contracts. Financial frictions not only distort the allocation of production factors (capital and entrepreneurial talents) but also slow down their reallocation process.

Motivated by the historical accounts of the miracle economies, we model the growth acceleration episodes as a process triggered by a large-scale economic reform that removes important sources of resource misallocation. We operationalize this idea by building upon 
the recent literature that emphasizes the role of idiosyncratic distortions/wedges (Restuccia and Rogerson, 2008; Hsieh and Klenow, 2009; Bartelsman et al., 2009). In particular, our pre-reform economy is the steady state of an economy subject to an exogenous process of idiosyncratic taxes and subsidies that distort individuals' production decisions. The largescale reform is then a once-and-for-all elimination of all such taxes and subsidies. We do not view these idiosyncratic distortions literally as taxes and subsidies. Rather, they are a parsimonious and transparent means of modeling individual/sector/size-specific policies, regulations, trade restrictions, and entry barriers that distort the allocation of resources across sectors and production units. We also note from the historical accounts that these reforms were implemented with underdeveloped financial markets in the background.

We quantitatively discipline our model in two steps. First, we calibrate the parameters that are invariant across countries and over time in a way that our undistorted, perfectcredit model economy matches the US data on standard macroeconomic aggregates, the size distribution of establishments and their dynamics. Second, as for the reform-related parameters, the degree of an economy's financial frictions is calibrated to the data on external finance to GDP ratios. The extent of the pre-reform idiosyncratic distortions is chosen to match the level changes in TFP and capital-to-output ratios between the reform date and the twentieth post-reform year. We then use our model to identify and quantify the role of initial resource misallocation and financial frictions in explaining the actual time paths of TFP and capital deepening over the same 20-year period in the miracle economies.

Our main exercise analyzes the transitional dynamics triggered by a sudden, unexpected reform that eliminates idiosyncratic distortions, with financial frictions remaining intact. This stark exercise is designed to highlight the transition dynamics that are wholly endogenous and intrinsic to the model. The model transition has three important features. First, the transition is gradual. Following the reform, GDP grows at an annualized rate of 3.7 percent for 16 years, and it takes 10.5 years for the capital stock to cover half the distance to the new, post-reform steady state - almost twice as long as the comparably-calibrated neoclassical transition. Second, the model generates endogenous dynamics of TFP, which increases by 4.9 percent per year for 7 years, although there is no further exogenous change after the reform. Third, the investment-to-output ratio rises over time, peaking 8 years after the reform. These rich dynamics reflect the process of unwinding much of the resource misallocation in the pre-reform economy that is slowed down by the frictions in financial markets.

In the pre-reform economy, resources are misallocated partly because of the financial frictions, but also because of idiosyncratic distortions: Subsidized entrepreneurs run larger operations and have more income and wealth than does their true productivity warrant, 
while the opposite is true for taxed entrepreneurs. The reform initiates a process of massive resource reallocation, but the underdeveloped financial market acts as a bottleneck: It takes time for productive-but-poor entrepreneurs to save up the collateral needed for starting a business and then operating at the efficient scale. This gradual reallocation - the entry and expansion of productive entrepreneurs and the downsizing and exit of incompetent ones losing subsidy - manifests itself in the slow pace of the transition overall, and more important, in the persistent TFP dynamics.

The investment rate dynamics are also explained by the gradual reallocation. Productivebut-poor entrepreneurs must save up enough collateral for entry and expansion, and have high saving rates. Those who lose subsidy are downsizing and exiting, and have much lower saving rates. Because of the idiosyncratic distortions in the pre-reform economy, the former account for only a small share of the aggregate wealth and income, while the latter, along with workers who also have low saving rates, account for a large share. The aggregate saving rate - equal to the investment rate in a closed economy - is an income-weighted average of the two groups' saving rates, and hence starts out low. Over time, those with high saving rates account for more and more wealth and therefore income, and the aggregate saving rate increases.

In subsequent exercises, we show that the transition dynamics we obtain require both frictions in financial markets and a reform that removes some sources of distortions. First, with perfect financial markets, the model is isomorphic to the neoclassical model, and a reform can only result in neoclassical dynamics. Intuitively, the reallocation process is instantaneous with perfect financial markets, and the initial misallocation has no lasting impact (Section 3.3.1). On the other hand, if the transition is triggered not by the removal of distortions but by a proportional improvement in production technology, the transition dynamics are very similar to the neoclassical dynamics, even in the presence of severe financial frictions. This is because there is no reallocation of resources to be done along the transition (Section 3.3.2).

In our exercises, in order to highlight the endogenous dynamics of the model, we drastically simplify actual reform episodes, which tended to be more protracted affairs and even prone to temporary reversals. Moreover, while financial market reforms were implemented much later and even more gradually than the removal of individual/sector/size-specific distortions, financial markets did improve over time. ${ }^{1}$ Our framework can easily incorporate

\footnotetext{
${ }^{1}$ Measured in both de jure and de facto sense, domestic financial market reforms lagged behind the removal of size-dependent or industry-specific distortions. Indeed, in policy circles, the removal of idiosyncratic distortions are categorized as "first-generation" reforms, while domestic financial markets are considered to fall into the domain of "second-generation" reforms, which comprise institutional reforms aimed at enhancing transparency and good governance in financial markets and corporate sectors (Camdessus, 1999; Navia and
} 
these facts, and indeed we consider a gradual financial development calibrated to the evolution of external finance to GDP in the data. Our results are found to be further strengthened (Section 3.3.3). With financial development, the financial markets are at its worst exactly when there is the most misallocation (i.e., at the beginning of the transition), and our gradual reallocation mechanism plays an even bigger role early on. Furthermore, the continued financial development in the latter stages of transitions results in even more persistent growth in GDP, TFP, and investment rates.

Our model provides a quantitative analysis of the macroeconomic dynamics following large-scale reforms. At the same time, the rich microeconomic heterogeneity in our model yields some salient micro-level implications that can be confronted with available data. In particular, the model predicts a spike in the reallocation of resources after the reform and a gradual increase in the size of the average establishment along the transition. We gather and compile available data and present evidence that supports our model in these dimensions (Section 4).

Related Literature Our study of the development dynamics of miracle economies relates to a recent literature on growth accelerations (Pritchett, 2000; Hausmann et al., 2005; Jones and Olken, 2008). Works in this literature use statistical techniques to identify structural breaks in growth series, and document the variables that correlate with growth accelerations. Large-scale economic reforms, as measured by Sachs and Warner (1995), are statistically significant predictors of sustained growth accelerations. Furthermore, consistent with our findings, the literature shows that the earlier stages of growth accelerations are driven by TFP growth that partly reflects more efficient labor reallocation, with capital accumulation playing a relatively minor role (Jones and Olken, 2005). We complement this literature with an in-depth study of 7 post-war miracle episodes, all of which are identified as incidents of sustained growth accelerations by the literature. We document that these growth accelerations follow large-scale reforms. We then quantitatively analyze the role of resource reallocation and financial development, and also present further empirical evidence on the reallocation of resources across sectors and plants following the reforms.

Christiano (1989) and King and Rebelo (1993) point out that the neoclassical transition dynamics are inconsistent with the observed growth experiences of economic miracles. They also study whether modified versions of the neoclassical growth model can account for the observed dynamics. The modifications include non-homothetic preferences, adjustment costs and a broader notion of capital, but all of them lead to some counterfactual implications for investment rates, interest rates and/or relative prices of installed capital and new investment

Velasco, 2003). 
goods. More recently, Chen et al. (2006) reconcile the neoclassical growth model with the post-war growth experience of Japan. They feed into the neoclassical model the realizations of the measured TFP path as an exogenous process, and show that the resulting dynamics are consistent with the data. In this context, we view our paper as an attempt at providing a theory of the TFP dynamics along the transitional paths based on the interaction of financial frictions and the initial misallocation of resources.

More recently, the disappointing growth experiences of post-communist countries have motivated many researchers to study economic transitions. This literature focuses on the reallocation of factors from state to private enterprises, with a particular emphasis on worker flows and labor market frictions (Blanchard, 1997). Our contention is that capital and entrepreneurial talents were inefficiently aligned during the communist era, and that financial frictions delayed efficient reallocation of capital even after the liberalization. ${ }^{2}$ Atkeson and Kehoe (1997) also attribute the delayed transition of these economies to misallocation of capital. In their model, capital cannot be swiftly reallocated across firms because it takes time for new private firms to accumulate complementary organizational capital.

We are building on the theoretical literature that counts financial frictions as a central issue on economic development - see Banerjee and Duflo (2005) for an exhaustive review of this literature. We develop this idea in ways that are empirically useful, by studying the transitional dynamics and the stationary equilibria of a broader class of quantitativelyoriented models with financial frictions. Giné and Townsend (2004) and Jeong and Townsend (2008, 2007) have pioneered quantitative analysis for this class of models. They estimate and calibrate models in this literature to the growth experience of Thailand. We share their interest in studying the role of financial frictions on transitional dynamics. However, in our main exercise we abstract from financial deepening which is the main driving force of their transition dynamics. Instead, we emphasize how, after reforms that eliminate important sources of misallocation, the joint distribution of ability and wealth evolves endogenously over time under financial frictions, starting from an initial condition characterized by resource misallocation. ${ }^{3}$

\footnotetext{
${ }^{2}$ In the communist economies, the allocation of capital was as likely to be determined by the distribution of power as by productivity. See Blanchard (1997) and Roland (2000) and the references therein. Calvo and Coricelli (1992) argue that credit market frictions inhibited efficient reallocation of capital in Poland after the liberalization.

${ }^{3}$ More specifically, our model incorporates forward-looking saving decisions and heterogeneity in returns to capital across entrepreneurs, both of which they abstract from.
} 


\section{Motivating Facts}

We present 5 common characteristics of the so-called development miracles. First, in most of these economies, economic growth took off following large-scale, economy-wide reforms. Second, even the miracles are protracted affairs, taking several decades to catch up with the richest economies. Third, a significant fraction of the economic growth is explained by the sustained growth in TFP. Fourth, the investment-to-output ratios are hump-shaped, increasing in the early stages of the growth acceleration and falling in the latter phases. Finally, these economies' financial markets have remained underdeveloped for the better part of the transitions.

To be more specific, we document the aggregate development dynamics of China, Japan, Korea, Malaysia, Singapore, Taiwan, and Thailand. These economies belong to the top decile in average growth rates during the 1960-2000 period. Furthermore, for each of these economies, one finds a large-scale economic reform that marks the beginning of the growth acceleration. ${ }^{4}$

Large-Scale Reforms Our perusal of the complex histories of the 7 countries and their reforms has led to the following reform dates: China, 1992; Japan, 1949; Korea, 1961; Malaysia, 1968; Singapore, 1967; Taiwan, 1959; and Thailand, 1983. We have also tried a purely statistical procedure to identify the beginning of growth accelerations following Hausmann et al. (2005) and Jones and Olken (2008), and we obtained strikingly similar dates. In fact, Hausmann et al. confirm that the beginning of many such acceleration episodes coincides with large-scale economic reforms. We proceed with our event-based approach because it allows us to be more explicit about the underlying events and policies that led to growth accelerations. In the appendix we provide a summary of these reform episodes for each country.

All the reforms that we identified above entailed large and broad changes in the economic structure. While each reform episode has idiosyncratic characteristics, these reforms involve the dismantling of import substitution regimes, the introduction of export-oriented policies (e.g., broadly-applied tax and credit advantages for exporters that did not distort the relative prices of tradables in the world market), and a substantial retrenchment of the

\footnotetext{
${ }^{4}$ The other economies in the top decile are Hong Kong, Ireland, and Romania, which we exclude from our analysis. For Hong Kong we could not identify large-scale reforms that can be used to date the beginning of their growth accelerations. Romania is not included because it was a non-market economy until the early 1990s, and also because its data exhibit erratic patterns. In the case of Ireland, its economic transformation followed the reforms in the late 1980s and the early 1990s that substantially liberalized local financial markets and international capital flows. In this regard, the Irish experience is sufficiently different from the others, and is not considered here. Having said so, our framework can be easily extended to accommodate such financial market reforms and capital account liberalizations, as is demonstrated in Sections 3.3.3 and 3.3.4.
} 
government's intervention in the economy. Another common component is the promotion of private firms' entry through a variety of measures, such as the deregulation of labor markets and the simplification of tax codes. In essence, the reforms resulted in more market-oriented economies, leading more productive firms and sectors to expand, and unproductive ones to contract. Naturally, such findings, together with more quantitative evidence on resource reallocation discussed in Section 4, have guided us in modeling large-scale reform episodes: We think of the pre-reform state as an economy stricken by idiosyncratic distortions or static wedges - as in Restuccia and Rogerson (2008) - and model a reform as the elimination of these idiosyncratic distortions that triggers macroeconomic transitions.
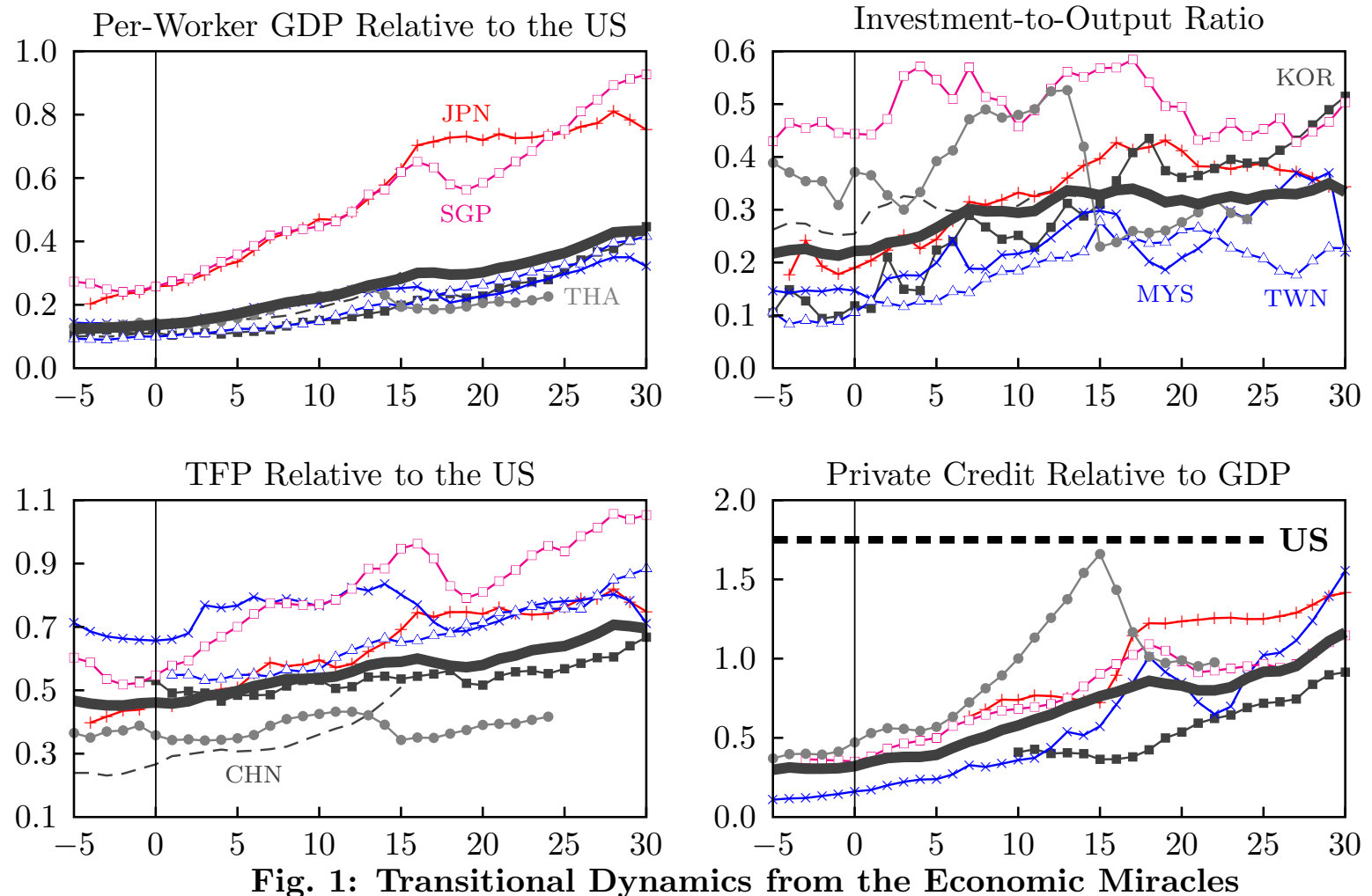

Post-Reform Transition Dynamics Figure 1 presents the main features of these economic miracles. The unweighted average across the 7 economies are shown with a thick gray line. ${ }^{5}$ For a given economy, year 0 on the horizontal axis is its date of large-scale reforms, and hence the beginning of its economic transition. A point on the horizontal axis therefore corresponds to different calendar years for different countries. The top left panel shows the evolution of the per-capita output in each country relative to the US value in each period.

\footnotetext{
${ }^{5}$ We deal with the unbalanced nature of our panel in the following way. First, we calculate the unweighted average for the balanced part of the panel. We then extrapolate this series forward and backward using the average growth rate of the countries with available data for given years.
} 
All these economies exhibit large and persistent output gains, which appear slow when seen through the lens of the neoclassical growth theory. A reasonably-calibrated neoclassical model - a capital share of one-third, a discount factor of 0.96 , an intertemporal elasticity of substitution of 0.67 , and a depreciation rate of 0.06 - predicts that it should take less than 6 years for aggregate capital stock to cover half the distance to the steady state. The data suggest a half-life of at least 15 years. $^{6}$

As shown in the bottom left panel, a significant fraction of the output gains is explained by productivity gains. Note that the standard neoclassical model-where TFP is an exogenously-given process - has nothing to say about the TFP dynamics. ${ }^{7}$

The top right panel depicts the behavior of investment-to-output ratios. In a neoclassical model, the investment-to-output ratios are monotonically decreasing along the transition to a steady state. In the data, investment rates actually start low and rise in the early stages of transitions. Only in the latter stages of transitions, are investment rates decreasing as predicted by the standard theory.

Finally, as shown in the bottom right panel, these economies are characterized by low levels of financial development as measured by the ratio of external finance to GDP. Our external finance measure is the sum of private credit owed to depository and other financial institutions as reported in Beck et al. (2000). For comparison, the average of this ratio for the US during the 1990-2005 period is 1.75 (dashed line). From the evolution of this indicator, one can see that financial development is achieved only in the latter phases of transitions. The average across countries of the external finance to GDP ratio during the first 20 years of transitions is less than $0.6^{8}$

We now construct a model with financial market imperfections and resource misallocation that captures and explains the observed growth experiences.

\footnotetext{
${ }^{6}$ To calculate the half-life in the data, we need to first take a stand on the long-run value of capital. We define it as the average over years 35 through 40 after the reforms. In this period, the per-worker capital relative to the US was stagnant on average, growing at an annual rate lower than 0.5 percent.

${ }^{7} \mathrm{TFP}$ for each country is relative to the US value in each period. We net out the contribution of human capital in our TFP construction. We measure human capital using a standard Mincerian framework, assuming a return of 13.4 percent per year for the first 4 years of schooling, 10.1 percent for the next 4 years, and 6.8 percent for the years thereafter. See, for example, Bernanke and Gürkaynak (2001). Capital stock series are constructed using the perpetual inventory method and an initial steady state assumption. We use a capital share of one-third. The data on GDP, investment rate, and the size of the workforce are from the Penn World Table 6.3.

${ }^{8}$ One exception is Thailand, which reformed its financial sector earlier than did other economies (Townsend, 2010). The sharp reversal around year 15 in the Thai series coincides with the 1997 financial crisis.
} 


\section{Model}

We propose a model with individual-specific technologies and imperfect financial markets to study the role of misallocation and reallocation of resources in macroeconomic transitions.

In each period, individuals choose either to operate an individual-specific technologyi.e., to become entrepreneurs - or to work for wage. This occupation choice allows for endogenous entry and exit in and out of the production sector, which are an important channel of resource allocation. Individuals are heterogeneous with respect to their entrepreneurial ability and wealth. Our model generates endogenous dynamics for the ability-wealth distribution, which turns out to be crucial for understanding macroeconomic transitions.

Imperfection in financial markets is modeled with a collateral constraint on capital rental that is proportional to an individual's financial wealth. This rental limit applies equally to all individuals in the economy.

In this section, we do not consider idiosyncratic distortions (or wedges). We introduce them into our model in Section 3.1.2 to construct the pre-reform economy.

Heterogeneity and Demographics Individuals live indefinitely, and are heterogeneous with respect to their wealth $a$ and their entrepreneurial ability $e \in \mathcal{E}$, with the former being chosen endogenously by forward-looking saving decisions. An individual's ability follows a stochastic process. In particular, individuals retain their ability from one period to the next with probability $\psi$. With probability $1-\psi$, an individual loses the current ability and draws a new entrepreneurial ability. The new draw is from a time-invariant ability distribution, and is independent of one's previous ability level. One can think of the ability shock as an arrival of a new technology making existing production processes obsolete or less profitable. In Section 3.1 we will calibrate this shock to be of a relatively low frequency - an average duration of ten years - to match the rate of establishment turnovers in the US data.

We denote by $\mu(e)$ the mass of type- $e$ individuals in the invariant distribution, with $e$ being assumed to be a discrete random variable. We denote by $G_{t}(e, a)$ the cumulative density function for the joint distribution of ability and wealth at the beginning of period $t$. For notational convenience, $G_{t}(a \mid e)$ is the associated c.d.f. of wealth for a given ability type $e$. The population size of the economy is normalized to one, and there is no population growth.

Preference All individuals discount their future utility using the same discount factor $\beta$. The preferences over the consumption sequence from the point of view of an individual in 
period $t$ are represented by the following expected utility:

$$
\mathbb{E}_{t} \sum_{s=t}^{\infty} \beta^{s-t} \frac{c_{s}^{1-\sigma}-1}{1-\sigma} .
$$

Technology In any given period, individuals can choose either to work for wage or to operate an individual-specific technology. We label the latter option as entrepreneurship. We assume that an entrepreneur with talent $e$ who uses $k$ units of capital and hires $l$ units of labor produces according to a production function $f(e, k, l)$, which is assumed to be strictly increasing in all arguments, and strictly concave in capital and labor, with $f(0, k, l)=0$. To be more specific, we use

$$
f(e, k, l)=e\left(k^{\alpha} l^{1-\alpha}\right)^{1-\nu},
$$

where $1-\nu$ is the span-of-control parameter. Accordingly, $1-\nu$ represents the share of output going to the variable factors. Out of this, fraction $\alpha$ goes to capital, and $1-\alpha$ goes to labor.

Throughout the paper, we assume that entrepreneurial ability is inalienable and that there is no market for entrepreneurial talents (potentially because of severe agency problems that we do not model explicitly). The labor market for workers is assumed to be perfectly competitive and frictionless. We now turn to the capital rental market, which is subject to contract enforcement problems.

Financial Markets Productive capital is the only asset in the economy. There is a perfectly-competitive financial intermediary that receives deposits, and rents out capital to entrepreneurs. The return on deposited assets - i.e., the interest rate in the economy-is $r_{t}$. The zero-profit condition of the intermediary implies that the rental price of capital is $r_{t}+\delta$, where $\delta$ is the depreciation rate.

We assume that entrepreneurs' capital rental $k$ is limited by a collateral constraint $k \leq \lambda a$, where $a \geq 0$ is individual financial wealth and $\lambda$ measures the degree of credit frictions, with $\lambda=\infty$ corresponding to perfect credit markets and $\lambda=1$ to financial autarky where all capital has to be self-financed by entrepreneurs. The same $\lambda$ applies to everyone in a given economy.

Our specification captures the common prediction from models of limited contract enforcement: The amount of credit is limited by individuals' wealth. At the same time, its parsimoniousness - the fact that financial frictions are captured by one single parameter, $\lambda$ enables us to analyze the quantitative effects of financial frictions on aggregate transitional 
dynamics without losing tractability. ${ }^{9}$

In this paper, we focus on within-period credit, or capital rental, for production purposes, and do not allow borrowing for intertemporal consumption smoothing; i.e., $a \geq 0$. This constraint will only bind for individuals who choose to be workers, and has no direct bearing on the behavior of entrepreneurs, who will need to hold assets to overcome the collateral constraint.

Individuals' Problem The problem of an individual in period $t$ can be written as:

$$
\begin{aligned}
& \max _{\left\{c_{s}, a_{s+1}\right\}_{s=t}^{\infty}} \mathbb{E}_{t} \sum_{s=t}^{\infty} \beta^{s-t} u\left(c_{s}\right) \\
& \text { s.t. } c_{s}+a_{s+1} \leq \max \left\{w_{s}, \pi\left(a_{s} ; e_{s}, w_{s}, r_{s}\right)\right\}+\left(1+r_{s}\right) a_{s}, \forall s \geq t
\end{aligned}
$$

where $e_{t}, a_{t}$, and the sequence of wages and interest rates $\left\{w_{s}, r_{s}\right\}_{s=t}^{\infty}$ are given, and $\pi(a ; e, w, r)$ is the profit from operating an individual technology. This indirect profit function is defined as:

$$
\pi(a ; e, w, r)=\max _{l, k \leq \lambda a}\{f(e, k, l)-w l-(\delta+r) k\} .
$$

Note that the collateral constraint $k \leq \lambda a$ is taken into account. Similarly, we denote the input demand functions by $l(a ; e, w, r)$ and $k(a ; e, w, r)$.

The max operator in the budget constraint stands for the occupation choice. A type$e$ individual with current wealth $a$ will choose to be an entrepreneur if his profit as an entrepreneur, $\pi(a ; e, w, r)$, exceeds labor income as a wage earner, $w$. This occupational choice can be represented by a simple policy function. Type- $e$ individuals decide to be entrepreneurs if their current wealth $a$ is higher than the threshold wealth $\underline{a}(e)$, where $\underline{a}(e)$ solves:

$$
\pi(\underline{a}(e) ; e, w, r)=w .
$$

Intuitively, individuals of a given ability choose to become entrepreneurs only if they are wealthy enough to overcome the collateral constraint and run their businesses at a profitable

\footnotetext{
${ }^{9}$ Our collateral constraint can be derived from the following limited enforcement problem. Consider an individual with financial wealth $a \geq 0$ deposited in the financial intermediary at the beginning of a period. Assume that he rents $k$ units of capital. Then he can abscond with fraction $1 / \lambda$ of the rented capital. The only punishment is that he will lose his financial wealth $a$ deposited in the intermediary. In particular, he will not be excluded from any economic activity in the future: He is even allowed to instantaneously deposit the stolen capital $k / \lambda$ and continue on as a worker or an entrepreneur. In the equilibrium, the financial intermediary will rent capital only to the extent that no individual will renege on the rental contract: $k / \lambda \leq a$.
} 
scale. Similarly, individuals of a given wealth level choose to become entrepreneurs only if their ability is high enough. ${ }^{10}$

With perfect credit markets, an individual's occupation depends solely on his ability and not on his wealth. There will be a threshold level of $e$ such that those with higher ability become entrepreneurs and the rest become workers. We provide more detail below.

Competitive Equilibrium Given $G_{0}(e, a)$, a competitive equilibrium consists of allocations $\left\{c_{s}\left(e_{t}, a_{t}\right), a_{s+1}\left(e_{t}, a_{t}\right), l_{s}\left(e_{t}, a_{t}\right), k_{s}\left(e_{t}, a_{t}\right)\right\}_{s=t}^{\infty}$ for all $t \geq 0$, sequences of joint distribution of ability and wealth $\left\{G_{t}(e, a)\right\}_{t=1}^{\infty}$, and prices $\left\{w_{t}, r_{t}\right\}_{t=0}^{\infty}$ such that:

1. Given $\left\{w_{t}, r_{t}\right\}_{t=0}^{\infty}, e_{t}$, and $a_{t},\left\{c_{s}\left(e_{t}, a_{t}\right), a_{s+1}\left(e_{t}, a_{t}\right), l_{s}\left(e_{t}, a_{t}\right), k_{s}\left(e_{t}, a_{t}\right)\right\}_{s=t}^{\infty}$ solve the individual's problem in (2) for all $t \geq 0$;

2. The labor, capital, and goods markets clear at all $t \geq 0$-in particular:

$$
\begin{array}{ll}
\sum_{e \in \mathcal{E}} \mu(e)\left[\int_{\underline{a}\left(e, w_{t}, r_{t}\right)}^{\infty} l\left(a ; e, w_{t}, r_{t}\right) G_{t}(d a \mid e)-G_{t}\left(\underline{a}\left(e, w_{t}, r_{t}\right) \mid e\right)\right]=0, & \text { (Labor Market) } \\
\sum_{e \in \mathcal{E}} \mu(e)\left[\int_{\underline{\underline{a}}\left(e, w_{t}, r_{t}\right)}^{\infty} k\left(a ; e, w_{t}, r_{t}\right) G_{t}(d a \mid e)-\int_{0}^{\infty} a G_{t}(d a \mid e)\right]=0 ; & \text { (Capital Market) }
\end{array}
$$

3. The joint distribution of ability and wealth $\left\{G_{t}(e, a)\right\}_{t=1}^{\infty}$ evolves according to the equilibrium mapping:

$$
G_{t+1}(a \mid e)=\psi \int_{u \leq a} \int_{a^{\prime}(e, v)=u} G_{t}(d v \mid e) d u+(1-\psi) \sum_{\hat{e} \in \mathcal{E}} \mu(\hat{e}) \int_{u \leq a} \int_{a^{\prime}(\hat{e}, v)=u} G_{t}(d v \mid \hat{e}) d u
$$

Perfect-Credit Benchmark With perfect capital rental markets, the production side of our model aggregates. This aggregate production function reflects the optimal allocation of individuals to entrepreneurship and of capital and labor to active entrepreneurs. In the absence of collateral constraints, individuals' wealth are irrelevant for production decisions.

The aggregate production function simplifies to:

$$
\begin{aligned}
& F(K)=A(\mu) K^{\alpha(1-\nu)} \\
& A(\mu)=\max _{e_{m}, 0<\iota \leq 1}\left(\sum_{e>e_{m}} \mu(e) e^{1 / \nu}+\iota \mu\left(e_{m}\right) e_{m}^{1 / \nu}\right)^{\nu}\left(\sum_{e<e_{m}} \mu(e)+(1-\iota) \mu\left(e_{m}\right)\right)^{(1-\nu)(1-\alpha)}
\end{aligned}
$$

Here $A(\mu)$ embodies the effect of the distribution of entrepreneurial ability on aggregate output. The threshold level for entrepreneurship is $e_{m}$. Given that we are assuming a discrete distribution of $e$, the choice of $\iota$ allows for the possibility that it may be optimal to assign only a fraction of the marginal ability types to entrepreneurship.

\footnotetext{
${ }^{10}$ Obviously, an individual's $e$ may be so low that he will never choose to be an entrepreneur. In this case, $\underline{a}$ should be thought of as $\infty$.
} 


\section{Quantitative Analysis}

The central objective of this paper is to construct a quantitative model of economic development that can capture and explain the rich macroeconomic transition dynamics observed in the data. Motivated by the historical accounts of the 7 miracle economies, we model the transition dynamics as a process triggered by a large-scale economic reform eliminating important sources of resource misallocation in the economy. We operationalize this idea by building on the recent literature that emphasizes the role of idiosyncratic distortions (or wedges) (Restuccia and Rogerson, 2008; Hsieh and Klenow, 2009; Bartelsman et al., 2009). In particular, our pre-reform state is the steady state of an economy where individuals are subject to an exogenous process of idiosyncratic taxes and subsidies. We then model the large-scale reform as a once-and-for-all elimination of all such taxes and subsidies. We emphasize that these idiosyncratic taxes and subsidies are merely a means of generating the pre-reform state in a disciplined and transparent manner. They stand in for the industrial policies, protectionism, entry barriers, sector- and/or size-dependent policies, a web of onerous and often-contradictory regulations, to name but a few, that have hindered economic development for many years. They are not meant to be literally taken as taxes and subsidies. We also note from the historical accounts that these reforms were implemented with underdeveloped financial markets in the background.

\subsection{Calibration}

In order to quantify our theory, we first calibrate a set of structural parameters - preferences, technologies, distribution of entrepreneurial ability - that remain invariant throughout. Then we calibrate a set of parameters that may change over the course of transitions - parameters governing idiosyncratic distortions and financial frictions. Once all these parameters are chosen, we use our model to construct the initial condition for our transition exercises, $G_{0}(e, a)$. This initial condition is the joint ability-wealth distribution in a stationary equilibrium with idiosyncratic distortions and underdeveloped financial markets.

\subsubsection{Parameters Invariant across Time and Economies}

The entrepreneurial ability $e$ is assumed to be a truncated and discretized version of a Pareto

distribution whose probability density is $\eta e^{-(\eta+1)}$ for $e \geq 1$. Each period, an individual retains his previous entrepreneurial ability with probability $\psi$. With probability $1-\psi$, he draws a new ability realization from the distribution of $e$ given above. Obviously, $\psi$ controls the persistence of ability, while $\eta$ determines the dispersion of ability in the population.

We here determine seven parameter values: two technological parameters, $\alpha$ and $\nu$; 
depreciation rate $\delta$; two parameters describing the ability process, $\psi$ and $\eta$; relative risk aversion coefficient $\sigma$, and subjective discount factor $\beta{ }^{11}$

We let $\sigma=1.5$ following the standard practice. The one-year depreciation rate is set at $\delta=0.06$. We choose $\alpha=0.33$. We are thus left with three relatively non-standard parameters, $\nu, \eta, \psi$, and the subjective discount factor, $\beta$. We calibrate them using as many relevant moments in the US data. They are: the employment share of the top decile of establishments by size; the share of earnings generated by the top twentieth of the population; the exit rate of establishments; and the real interest rate.

To be more specific, we calibrate our model with perfect capital markets $(\lambda=\infty)$ to match these moments in the US. We allow for the possibility that the average entrepreneurial productivity in the US is higher than in less developed economies, reflecting human capital and exogenous aggregate productivity differences. ${ }^{12}$ As the primary mechanism of our model concerns the allocation of resources among heterogeneous producers, our calibration and results are not affected by such cross-country differences in the mean level of entrepreneurial productivity. ${ }^{13}$

In mapping our model to the data, establishments are our preferred unit of analysis because we think they embody production technologies. Our explicit assumption is that one entrepreneurial operation in the model is an establishment in the data. Under our assumption that the US is the perfect-credit benchmark, our model is consistent with the presence of firms with multiple establishments in the data, because the firm-establishment correspondence does not affect the production side of the economy at all - in particular the establishment size distribution — with perfect credit markets.

The first column of Table 1 shows the moments in the US data. The decile with the largest - measured by employment - establishments in the US accounts for 67 per cent of the total employment in 2000. We target the earnings share of the top twentieth of the population (0.3 in 1998), and an annual establishment exit rate of 10 percent reported in the US Census Business Dynamics Statistics. Finally, as the target interest rate, we pick 4.5

\footnotetext{
${ }^{11}$ Recall that the entrepreneurial production technology is $e\left(k^{\alpha} l^{1-\alpha}\right)^{1-\nu}$.

${ }^{12}$ That is, for the US, one can use the following production function with $A_{U S}>1$ :

$$
f(e, k, l)=A_{U S} e\left(k^{\alpha} l^{1-\alpha}\right)^{1-\nu} .
$$

${ }^{13}$ One can consider introducing exogenous differences across countries in the higher-order moments of the entrepreneurial ability distribution. The difficulty here is that the available data do not provide enough guidance or discipline on the direction and magnitude of cross-country variations in these moments. Even without such exogenous differences in the higher-order moments of the underlying entrepreneurial ability distribution, however, our model endogenously generates different distributions of productivity among active entrepreneurs for economies with different degrees of financial frictions or idiosyncratic distortions.
} 


\begin{tabular}{lccl}
\hline & US Data & Model & Parameter \\
\hline Top 10\% Employment & 0.67 & 0.67 & \\
Top 5\% Earnings & 0.30 & 0.30 & $\eta=4.15, \nu=0.21$ \\
\cline { 3 - 4 } Establishment Exit Rate & 0.10 & 0.10 & $\psi=0.894$ \\
\cline { 3 - 4 } Real Interest Rate & 0.045 & 0.045 & $\beta=0.904$ \\
\hline
\end{tabular}

Table 1: Calibration

percent per year.

The second column of Table 1 shows the moments simulated from the calibrated model. Even though in the model economy all four moments are jointly determined by the four parameters, each moment is primarily affected by one particular parameter. Given the spanof-control parameter $1-\nu$, the tail parameter of the talent distribution $\eta$ can be inferred from the tail of the employment distribution. We can then infer $\nu$ from the earnings share of the top five percent of the population. Top earners are mostly entrepreneurs both in the data and in our model, and $\nu$ controls the share of output going to the entrepreneurial input. These two parameters are calibrated at $\nu=0.21$ and $\eta=4.15$. The parameter $\psi=0.894$ leads to an annual exit rate of 10 percent in the model. Note that $1-\psi$ is larger than 0.1 , because a fraction of those hit by the idea shock chooses to remain in business. Entrepreneurs exit only if their newly-drawn ability is below the equilibrium cutoff level. Finally, the model requires a discount factor of $\beta=0.904$ to attain an interest rate of 4.5 percent per year.

\subsubsection{Parameters for Idiosyncratic Distortions and Financial Frictions}

We model the initial condition of our transition exercises as the joint ability-wealth distribution in a stationary equilibrium under financial frictions and idiosyncratic distortions. We model the latter as individual-specific (or idiosyncratic) taxes/subsidies/wedges on output $\tau_{y i}$ that distort the static profit-maximization problem of entrepreneur $i$ into:

$$
\left(1-\tau_{y i}\right) e_{i}\left(k_{i}^{\alpha} l_{i}^{1-\alpha}\right)^{1-\nu}-w l_{i}-(\delta+r) k_{i}, \quad k_{i} \leq \lambda a_{i}
$$

The important distinction is that our financial frictions apply equally to everyone in the economy $-\lambda$ has no individual subscript - while $\tau_{y i}$ is individual specific, as the explicit index $i$ emphasizes. We could alternatively assume that idiosyncratic distortions take the form of taxes/subsidies on capital or labor, and still obtain similar results.

We reiterate here that $\tau_{y i}$ 's are merely a transparent and parsimonious means of operationalizing the pre-reform distortions and their removal through a reform. We do not have 
to view them literally as taxes or subsidies. ${ }^{14}$

For the sake of parsimoniousness, we assume that $\tau_{y}$ is a random variable with only two possible outcomes: $\tau_{+}(\geq 0)$ and $\tau_{-}(\leq 0)$. Also, the probability of being taxed for a type-e individual, $\operatorname{Pr}\left\{\tau_{y}=\tau_{+} \mid e\right\}$, is assumed to be $1-e^{-q e}$. The literature - e.g., Restuccia and Rogerson (2008) - shows that such idiosyncratic distortions have larger adverse effects when $\tau_{y}$ and $e$ are positively correlated, which in our parametrization requires $q>0$-because $\tau_{+}$ and $\tau_{-}$are the same for all $e$.

Now we have 3 parameters, $\tau_{+}, \tau_{-}$, and $q$, which are then chosen to match the following three moments. First, measured TFP relative to the US increased by one-third after 20 years of post-reform transitions, when averaged across the 7 transition episodes we study in Section 1. Second, the capital-to-output ratios increased by 37 percent over the same 20-year span. ${ }^{15}$ Finally, we impose budget balance on the pre-reform stationary equilibrium. While we do not think of the idiosyncratic distortions literally as taxes and subsidies, we find that this assumption gives us a sensible benchmark. In the end, we have $\tau_{+}=0.57, \tau_{-}=-0.15$, and $q=1.55$.

As for the financial friction parameter, we pick $\lambda=1.35$, which corresponds to a steadystate external finance to GDP ratio of 0.6 in an economy without idiosyncratic distortions, which is the time average of the cross-country average series over the period that begins 5 years before and ends 25 years after the reforms in Section 1. In Section 3.3.3, we also consider a gradual financial development (i.e., a sequence of $\lambda$ 's that increases over time) that matches the evolution of the external finance to GDP ratios in the data.

We now compute the stationary equilibrium with idiosyncratic distortions and financial frictions. The resulting joint distribution of wealth and ability is the initial condition of our benchmark transition exercises in Section 3.3.1. This joint distribution is characterized by wealth being misallocated across ability types, when compared with the stationary distribution of an economy without idiosyncratic distortions.

\subsection{Long-Run Impact of Financial Frictions}

We first show the long-run effect of financial frictions on the equilibrium output, aggregate productivity, and interest rate. We vary $\lambda$-the parameter governing the enforcement of contracts - from 1 (financial autarky) to $\infty$ (perfect credit), which span external finance to GDP ratios from 0 to 1.74. This is the empirically relevant range: In Beck et al. (2000),

\footnotetext{
${ }^{14}$ One interpretation is that the returns to entrepreneurial abilities are distorted idiosyncratically by government policies and interventions. The retreat of the government can then be thought of as the reduction or removal of $\tau_{y i}$ 's, which re-aligns the returns to entrepreneurial abilities.

${ }^{15}$ The idea is that we fix the magnitude of long-run changes in TFP and capital-output ratios, and evaluate the speed and the shape of the model transition dynamics.
} 
the bottom quartile of the cross-country distribution of external finance to GDP ratios is 0.13, while the figure for the US, one of the most financially developed economies, is 1.75 . The parameter $\lambda$ itself has no immediate empirical counterpart. Hence we plot our model simulations against the endogenous ratio of external finance to GDP implied by a given $\lambda$. The equilibrium external finance to GDP ratio is monotonically increasing in $\lambda$, with a lower $\lambda$ corresponding to more financial frictions.

There are no idiosyncratic distortions in this analysis, as we focus on the marginal effect of financial frictions.
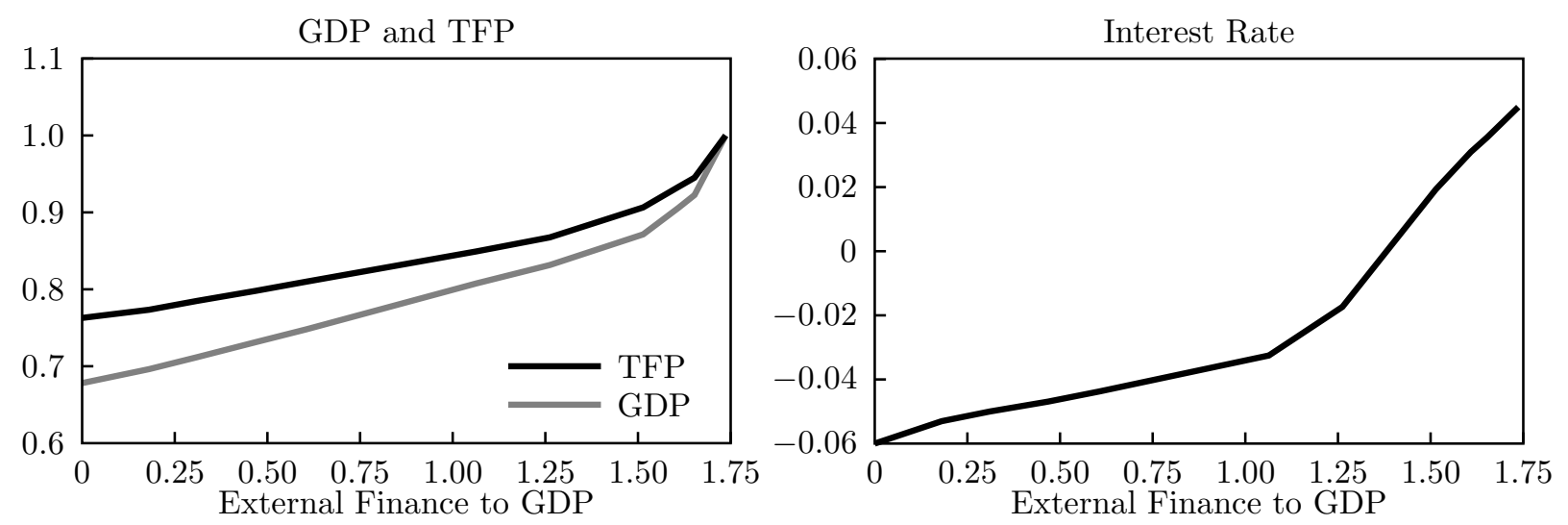

Fig. 2: Long-Run Effect of Financial Frictions

In the left panel of Figure 2, we plot the GDP and TFP in the steady state for a given $\lambda$. They are normalized by their respective value in the perfect-credit case. In our model, the variation in financial frictions can bring down output per worker by about 30 percent from the perfect-credit level. This is tantamount to about half of the output per worker difference between Mexico and the US. The magnitude is nevertheless sizable, considering that we are varying one single factor - financial markets - across countries. As in the data, the per-capita income differences in our model are primarily accounted for by differences in TFP. Financial frictions can reduce aggregate TFP by 24 per cent in our model.

These effects reflect the distortions on production decisions at the intensive and the extensive margin. Intuitively, financial frictions distort the allocation of productive capital among entrepreneurs in operation. Those with binding collateral constraints will operate at inefficiently small scales. Financial frictions also distort the entry and exit decisions of entrepreneurs: Productive-but-poor entrepreneurs delay entry until they can overcome financing constraints, and incompetent-but-wealthy ones remain in business. Such misallocation is captured in aggregate productivity measures, and explains the lower output in economies with financial frictions.

The right panel shows that equilibrium interest rates are lower in economies with tighter collateral constraints (and hence less external financing). Tight collateral constraints (i.e., 
low $\lambda$ 's), holding other things constant, restrict entrepreneurs' demand for capital $(k \leq \lambda a)$, and at the same time increase their self-financing needs and hence saving rates (i.e., a larger supply of capital). Therefore, the equilibrium interest rate is lower with tighter collateral constraints. This prediction of our model is consistent with empirical findings and also the prevalence of "financial repression" in less developed countries (McKinnon, 1981; Ohanian and Wright, 2008). ${ }^{16}$

These results give a sense of the impact of financial frictions on the macroeconomy in the long run. At the same time, the magnitude of the impact suggests that financial frictions have significant impact on macroeconomic transitions as well, which we confirm in the next section.

Before we proceed, we briefly discuss what aspects or calibrations of our economy are essential for financial frictions to have meaningful effects. In particular, we focus on two parameters: $\psi$, which controls the persistence of shocks, and $\eta$, which controls the dispersion of entrepreneurial productivity.

Shock persistence has two disparate effects. First, it determines what fraction $(1-\psi)$ of individuals will re-draw their ability. If the economy is in a steady state, it can be interpreted as a measure of how much resource reallocation is needed each period, with low persistence (low $\psi$ ) implying more need for the reallocation of production factors among producers. Second, it determines the likelihood of talented-but-poor entrepreneurs overcoming collateral constraints over time by accumulating collateral. It takes time to accumulate wealth or collateral, and if the individual productivity is not persistent and hence the profitable opportunities are only short-lived, self-financing is a less effective substitute for credit markets.

Therefore, holding other things equal, the less persistent the shocks are, the larger the impact of financial frictions is. This intuition becomes even clearer if one considers the extreme cases. If the shock is completely permanent, i.e. $\psi=1$, financial frictions have no impact whatsoever in the steady state: All the talented entrepreneurs eventually overcome the financial frictions by accumulating enough collateral, and there is no need for reallocating such resources among producers. On the other extreme, we have worked out a version of our model with $\psi=0$; that is, a case where ability shocks is purely i.i.d. over time, again holding all other parameters constant. Going from perfect credit $(\lambda=\infty)$ to financial autarky $(\lambda=1)$, we find a 61-percent drop in the steady-state GDP, which is nearly twice

\footnotetext{
${ }^{16}$ This result does not contradict the fact that the cost of capital could be higher in countries with higher financial intermediation costs. Firstly, economies with higher intermediation costs tend to have a higher spread between deposit and lending rates. We could introduce this feature into our model without much difficulty, but it will not change our main results. Secondly, one can think of the quantity-constrained entrepreneurs in our model as being subject to a prohibitively high marginal (shadow) rental rate of capital.
} 
the impact of financial frictions in our calibration of $\psi=0.89$. While these results are based on comparisons across steady states, they clearly suggest that the transition dynamics should be particularly susceptible to financial frictions when shocks are not too persistent.

The other parameter of interest is $\eta$, which controls the degree of heterogeneity in entrepreneurial productivity. The adverse effect of financial frictions in our model materializes through two channels: the misallocation of entrepreneurial talent (extensive margin) and the misallocaiton of capital (intensive margin). If there is more heterogeneity and dispersion in entrepreneurial talent (a lower $\eta$ ), there is a larger extent to which entrepreneurial talent can be misallocated, and hence the effect of financial frictions will be larger. ${ }^{17}$

To quantify this intuition, we have worked out a version of our model with $\eta=6.225$, which implies less dispersion in entrepreneurial talent, holding all other parameters fixed at their levels in Section 3.1.1. This 50 percent increase in $\eta$ (from 4.15) translates into less concentration in the establishment size distribution: With perfect credit markets, now the decile of largest establishments accounts for 45.3 percent of the total employment, down from 67 percent in Section 3.1.1. Now, going from perfect credit $(\lambda=\infty)$ to financial autarky $(\lambda=1)$, we find a 27-percent drop in the steady-state GDP; that is, the impact of financial frictions on long-run GDP is about 15 percent smaller with $\eta=6.225$ than with $\eta=4.15$. This steady-state result suggests that the effect of financial frictions will be larger when there is more heterogeneity in entrepreneurial productivity (i.e., a smaller $\eta$ ), although the magnitude of the impact is not too sensitive to this particular parameter.

\subsection{Post-Reform Transition Dynamics}

\subsubsection{Benchmark Exercise: Removal of Idiosyncratic Distortions}

In this exercise, we study the transitional dynamics triggered by a sudden, unexpected reform that eliminates all idiosyncratic distortions. Once the reform is implemented, everyone correctly understands that it is a permanent change.

We assume that domestic financial frictions remain the same (at $\lambda=1.35$ ) throughout the transition period. The reform experiences of the countries we study in Section 1 are consistent with this sequencing of reforms. Measured in both de jure and de facto sense, domestic financial market reforms lagged behind the removal of size-dependent or industryspecific taxes and subsidies (so-called first-generation reforms).

This is a very stark exercise, and simplifies actual reform episodes which tended to be more gradual. The removal of idiosyncratic distortions was often a protracted affair, even

\footnotetext{
${ }^{17}$ Obviously, more dispersion in entrepreneurial talent necessitates more dispersion in the efficient scale of operation. As a result, there is also a larger extent to which capital can be misallocated among active entrepreneurs, leading to a larger impact of financial frictions along the intensive margin.
} 
prone to temporary reversals in some cases. In addition, while financial market reforms were implemented much later and even more gradually than the first-generation reforms, financial markets did improve over time. Our framework can incorporate these facts, and indeed we consider a gradual financial development in Section 3.3.3, which is found to further strengthen our results.

The additional exogenous dynamics regulated by the pace of reforms will give us more degrees of freedom and hence only help us even more closely match the empirical patterns in Section 1. The advantage of our stark exercise is that the dynamics following the reform are wholly endogenous and intrinsic to the model, providing a theory of transitional dynamics that is built on resource misallocation and financial frictions.

In Figures 3 and 4, we show the transition dynamics following this stark reform. We collate the model simulation results (black solid lines) with two other series. One is the corresponding data from Section 1 , shown with gray solid lines. ${ }^{18}$ The other is the transition dynamics from a standard neoclassical model that is comparably calibrated (dotted lines). To be more specific, we use a version of our model with perfect capital rental markets $(\lambda=\infty)$, which is isomorphic to the standard neoclassical model. We then apply the same calibration strategy for $\tau_{+}, \tau_{-}$, and $q$ to construct the initial condition for this perfect-credit transition: After the transition, TFP is one-third higher, and capital-to-output ratio is 37 percent higher, while the taxes and subsidies net out in the distorted initial steady state.

Aggregate output, capital stock and measured TFP are normalized by their respective levels in the pre-reform steady state. ${ }^{19}$ Investment-to-output ratios are reported as deviations from the pre-reform levels.

Three facts stand out.

First, our model transition to the new steady state is slower than the neoclassical dynamics. As shown in the left panel of Figure 4, it takes 10.5 years for capital stock to cover half the distance to the new steady state in our model, while it takes only 5.5 years in the comparable neoclassical model. In fact, the capital stock in the model closely matches the data for as many as 15 years following the reform.

Second, the model generates an endogenous TFP dynamics, although there is no additional exogenous change after the reform in year 0 . This reflects more efficient reallocation of resources over time both at the extensive and the intensive margins, as production shifts from

\footnotetext{
${ }^{18}$ As our model abstracts from the rise in labor force participation and educational attainment along the economic transitions, we report capital and output per effective unit of labor. That is, we divide capital stock and GDP by the number of workers adjusting for the average human capital in the population. We have already used the same procedure to construct the TFP series in Section 1.

${ }^{19}$ To be consistent with our TFP calculation in the data, we assign one-third of entrepreneurial income to capital and the rest to labor. Given our calibration of $\alpha$, we are using a capital share of one-third (and a labor share of two-thirds) overall.
} 

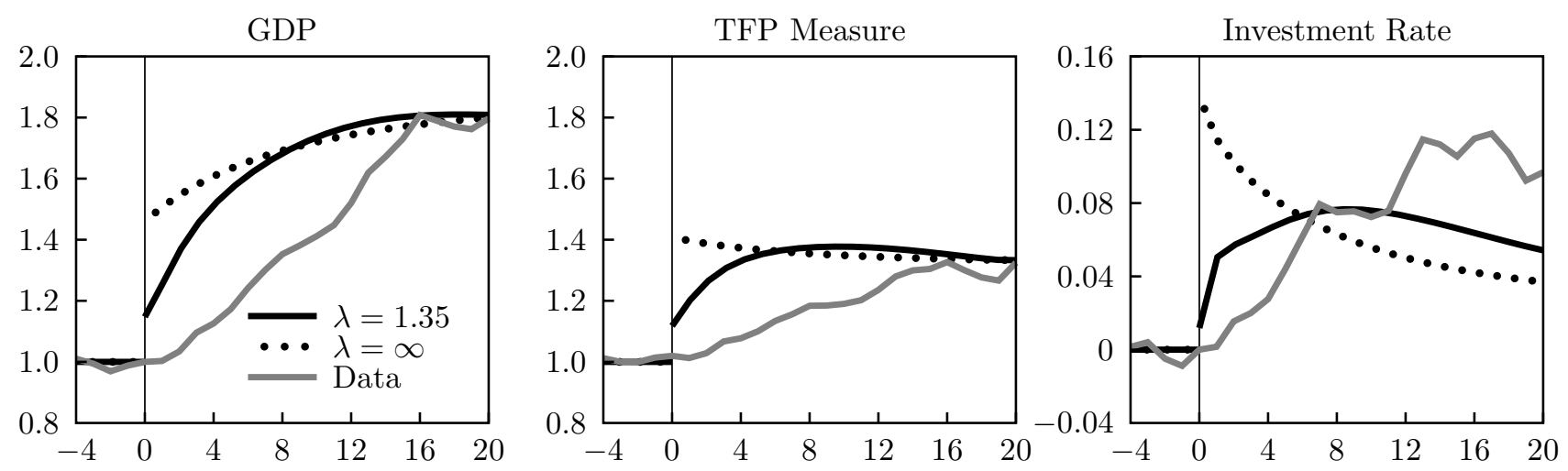

Fig. 3: Benchmark Transition, Aggregate Dynamics I
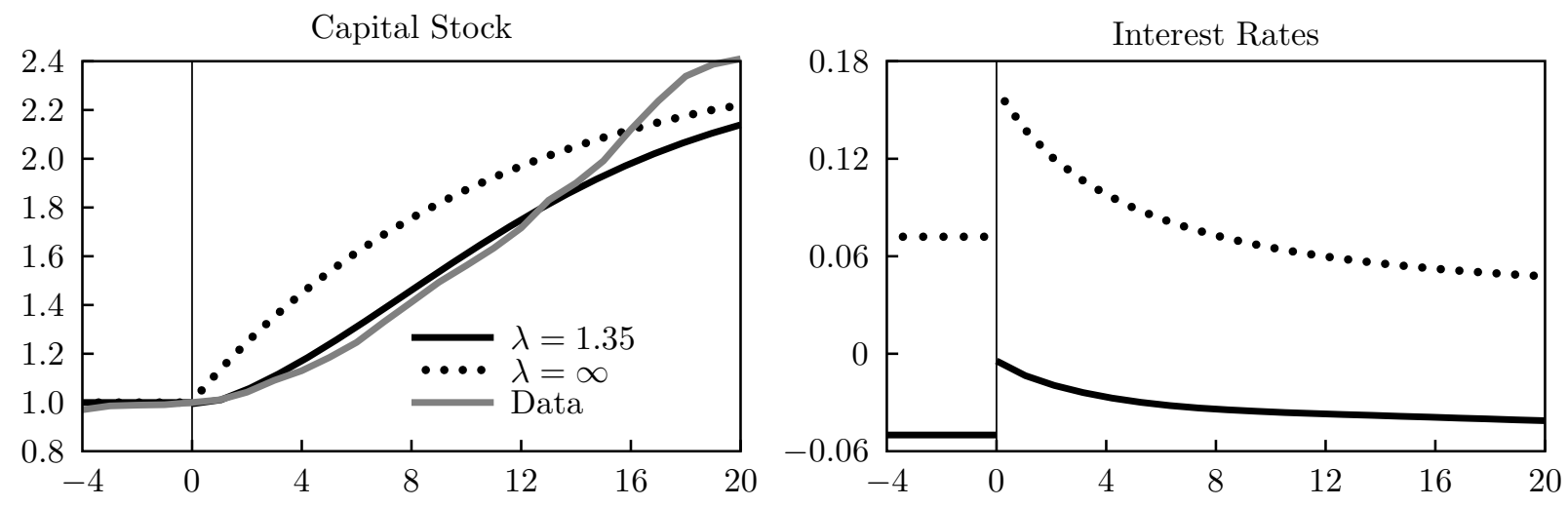

Fig. 4: Benchmark Transition, Aggregate Dynamics II

the previously-subsidized entrepreneurs to the productive entrepreneurs previously stunted by idiosyncratic taxes. The reallocation is gradual, as it is intermediated through imperfect financial markets. On the contrary, with perfect credit markets, our model aggregates into a standard neoclassical growth model, which is devoid of endogenous TFP dynamics apart from the instantaneous jump reflecting the removal of the idiosyncratic distortions.

Third, the investment-to-output ratio is hump-shaped, in contrast to the monotonically decreasing pattern of neoclassical models. This reflects the evolution of the joint distribution of wealth and entrepreneurial productivity, as well as individuals' heterogenoues saving behavior.

We now explore these three facts in more detail.

In the pre-reform steady state, which is our initial condition for the transition, economic resources are misallocated partly because of the financial frictions, but also because of the idiosyncratic distortions. Subsidized entrepreneurs run larger operations and accumulate more wealth than is warranted by their true productivity, while the opposite is true for taxed entrepreneurs. Idiosyncratic distortions also distort entry into entrepreneurship, propping up incompetent entrepreneurs with subsidies and keeping out talented ones with taxes. 
From year 0 on, as the reform eliminates idiosyncratic distortions, resources are reallocated more efficiently. Reallocation occurs along two margins. First, capital and labor are reallocated among existing entrepreneurs (intensive margin). In addition, more productive entrepreneurs previously taxed out of entrepreneurship will enter into business, while previously-subsidized incompetent entrepreneurs will exit (extensive margin). The reallocation along these two margins occurs gradually over time, slowed down by the frictions in the financial market: It takes time for a talented-but-poor entrepreneur to save up the collateral needed for operating at a profit-maximizing scale.

The more efficient reallocation along these margins is reflected on the measures of TFP, which increase over time. As the reallocation is subject to the financial frictions, the increase in TFP exhibits protracted endogenous dynamics that reflect the interaction between the initial misallocation and financial frictions. GDP also increases following the reform, largely mirroring the increase in TFP early on (first 6 years) and the accumulation of capital later (next 15 years or so).
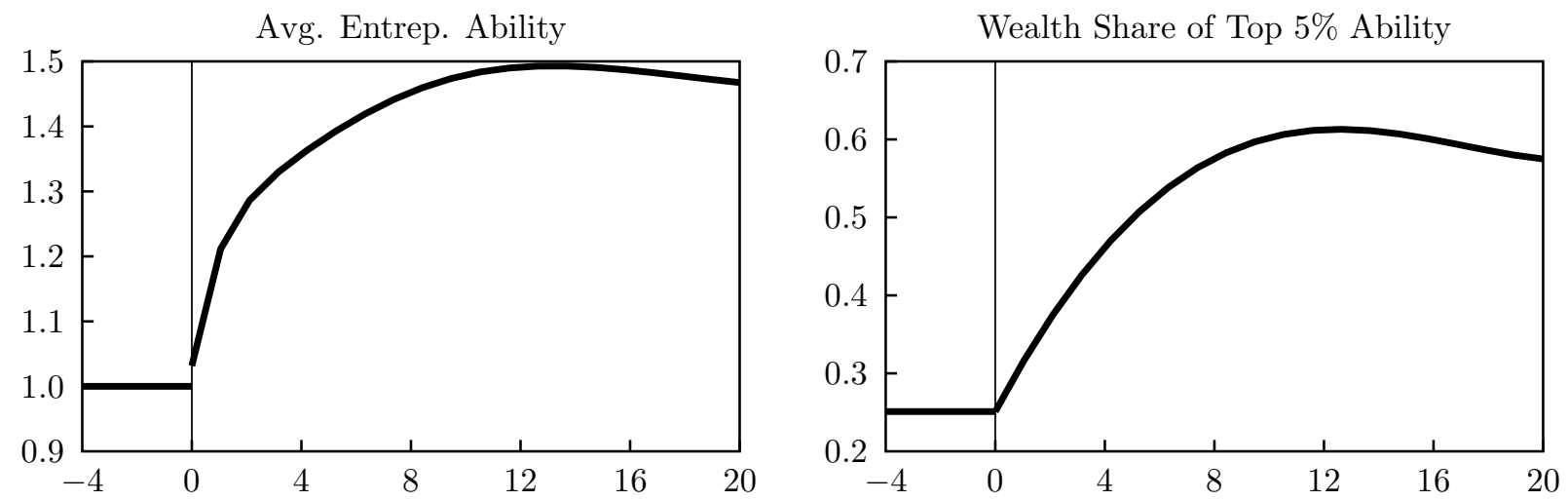

Fig. 5: Benchmark Transition Micro-Implications

In Figure 5, we show in more detail the reallocation at the extensive and the intensive margins. The left panel shows the average entrepreneurial productivity $(e)$ among active entrepreneurs, normalized by its pre-reform value. The average increases over time, reflecting the exit of the incompetent entrepreneurs who lose their subsidy and the entry of the productive entrepreneurs previously kept out by idiosyncratic taxes. The exits are not instantaneous, because subsidized entrepreneurs tend to be rich in the pre-reform economy, and their wealth offers them an advantage in entrepreneurship in the presence of financial frictions (tight collateral constraints). Likewise, the entries are not instantaneous, because taxed entrepreneurs tend to be poor in the pre-reform economy, and they need to save up enough collateral to start producing at a profitable scale.

The reallocation of production factors at the intensive as well as the extensive margins is reflected on the evolving wealth distribution in the economy. In the right panel of Figure 5, 
we show the fraction of the aggregate wealth held by those in the top five percentiles of the entrepreneurial productivity distribution. ${ }^{20}$ Those in this group are either active or soonto-be entrepreneurs, and were more likely to be taxed than subsidized in the pre-reform economy. With the idiosyncratic taxes gone, they would like to scale up to the maximal profit level, but they are still subject to the collateral constraint. Naturally, they have a strong self-financing motive to overcome the collateral constraint, and this motive is an important driver of their saving and hence wealth. Their wealth share rapidly rises from 25 percent of the aggregate wealth in the pre-reform economy to 60 percent. By contrast, the rest of the population are mostly workers after the reform, and hence do not have a self-financing motive. Their wealth share initially declines as they consume according to a higher permanent income brought on by the reform (i.e., wage increases over time), and also as the previously-subsidized entrepreneurs run down their wealth as they soon cease to derive collateral services from their wealth. ${ }^{21}$

These very forces shape the hump in the investment-to-output ratio during the postreform transitions. Following the reform, productive entrepreneurs - such as those in the top five percentiles of ability - have very high saving rates, largely motivated by the need to overcome collateral constraints through self-financing. However, because of the idiosyncratic distortions in the pre-reform days, they account for a relatively small fraction of the aggregate income and wealth. On the other hand, the others have low, even negative, saving rates: For workers, their wage will increase over time, and hence they will run down their wealth or try to borrow; For entrepreneurs who lose their subsidy, their wealth will stop providing collateral services as they downsize and exit from entrepreneurship, and hence they will also run down their wealth. Initially, those with low saving rates account for much more income than those with high saving rates, and therefore, the aggregate saving rate (income-weighted average of individual saving rates) - and hence investment rate in a closed economy - starts out low. Over time, as in Figure 5, those with high saving rates account for more and more wealth and therefore income, and the aggregate saving rate increases. Eventually, with enough wealth and hence collateral, the saving rate of even the most productive entrepreneurs start to fall, as in the neoclassical dynamics. This investment-to-output ratio dynamics are embedded in the transition of aggregate capital, which barely increase for the first 3 years following the reform, only to accelerate later and eventually decelerate into the new steady state. It takes 10.5 years to cover half the distance to the new steady state, which is almost half the speed

\footnotetext{
${ }^{20}$ With the stochastic productivity process, the identities of those in this group change over time.

${ }^{21}$ Figure 5 will also turn out to accord with a unique micro-level prediction of our model. Although the unavailability of data precludes direct empirical evidence on average entrepreneurial productivity or wealth shares by entrepreneurial ability, in Section 4 we present indirect evidence of these series in Figure 5 by compiling data on the evolution of average establishment size.
} 
of the comparably-calibrated neoclassical model, i.e., a model with perfect credit markets (dotted lines).

By contrast, with perfect credit markets, once the idiosyncratic distortions are eliminated, the evolution of the wealth distribution is irrelevant for transition dynamics, except for the first moment (aggregate capital). Thus, any misallocation in the initial condition is irrelevant for transition dynamics. The standard features of the neoclassical transitions are confirmed. First, the transition is fast. It takes only 5.5 years (rather than 10.5) to cover half the distance to the new steady state. For GDP, with the immediate increase in TFP, the transition is even faster: GDP jumps up nearly by 50 percent immediately. Second, as the initial capital stock is now less than half of the new steady-state level, the marginal product of capital is very high initially, and falls over time with capital accumulation. This explains the monotonically decreasing interest rates (from an unrealistically high level) and the same pattern in the investment-to-output ratio.

In summary, it is made clear that the rich dynamics in the benchmark exercise are driven by the financial frictions slowing down the reallocation of initially misallocated resources. Without financial frictions, initial misallocation becomes irrelevant as soon as idiosyncratic distortions are eliminated, and our model aggregates to a standard neoclassical growth model. In other words, the history of initial misallocation does not persist.

\subsubsection{Initial Condition without Idiosyncratic Distortions: Technology Shock}

We now show that the initial misallocation of wealth and talent is also necessary for the rich transitional dynamics in the benchmark exercise.

To emphasize the interaction between initial misallocation and financial frictions that drives the rich transition dynamics in Section 3.3.1, we now construct an initial condition that has the same degree of misallocation as the new steady state. To have the same degree of resource misallocation before and after the transition, we must rule out the reform that eliminates idiosyncratic distortions. As we are interested in isolating the role of initial misallocation, we hold fixed the degree of financial frictions before and after the transition at $\lambda=1.35$, as in our benchmark exercise.

Therefore, while in the benchmark exercise, the transition was triggered by the removal of idiosyncratic distortions, we will need to come up with another way of, first, generating the difference between the initial and the new steady states, and, second, triggering the transition from the former to the latter. We decide to use a permanent, proportional change in the entrepreneurs' production functions.

More specifically, we construct the initial condition by computing the steady state of an economy with $\lambda=1.35$ and no idiosyncratic distortions. Starting from this initial condition, 
we assume that the economy is hit in year 0 by a sudden, unexpected permanent technology shock that increases all individuals' productivity proportionately by one-third, the magnitude by which the measured TFP increased in the transition of Section 3.3.1. The resulting transition dynamics are shown in Figure 6.
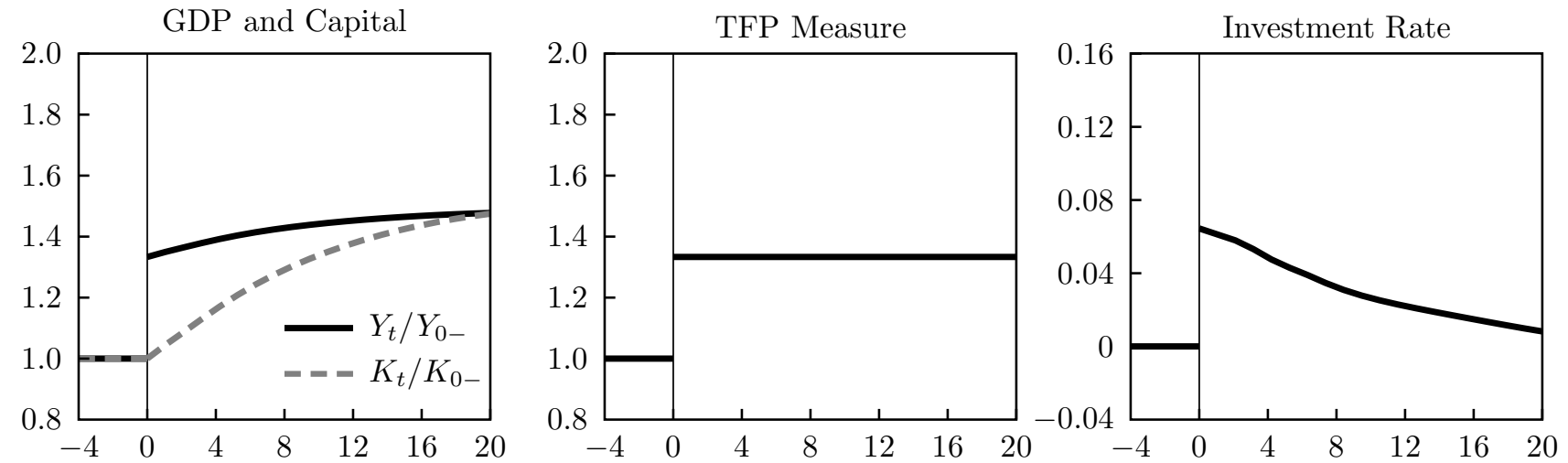

Fig. 6: Transition Dynamics without Misallocation to Unwind

Compared to the benchmark exercise, the transition is faster, with aggregate capital covering half the distance to the new steady state in 8 years (rather than 10.5), although the degree of financial frictions is the same in both exercise $(\lambda=1.35)$. What is more interesting, the investment-to-output ratio jumps up and then declines over time, as in the neoclassical transition.

Furthermore, because the degree of misallocation is constant over time here (i.e., no change in idiosyncratic distortions or $\lambda$ ), the measured TFP exhibits no meaningful endogenous dynamics, apart from the jump caused by the exogenous aggregate productivity shock.

To sum, this exercise considers a transition along which the degree of misallocation is constant. In particular, there is no idiosyncratic distortion all along, and the financial frictions $(\lambda=1.35)$ are held constant throughout. The transition is driven by a permanent aggregate productivity shock. The transition dynamics are qualitatively similar to the neoclassical dynamics, even though the transition is subject to financial frictions. As there is no notion of misallocation being unwound through the imperfect financial market, financial frictions have little impact on the transition dynamics. In other words, there is no history to be prolonged by financial frictions.

The rich dynamics of Section 3.3.1 capture the interaction between the force unwinding initial misallocation (e.g., a reform that removes idiosyncratic distortions) and the financial frictions that slow down this force. If either is missing, the transitions are at least qualitatively indistinguishable from the standard neoclassical dynamics. 


\subsubsection{Reform and Financial Development}

The benchmark exercise assumes that idiosyncratic distortions are eliminated all at once, and that financial frictions remain the same throughout. These assumptions are made so that we can better understand and emphasize the transition dynamics intrinsic to the model. At the same time, we acknowledge that actual reforms tended to be more gradual, and that domestic financial markets did improve over time - albeit at a slower pace than reforms in other dimensions.

Here, we relax the second assumption, and incorporate an exogenous financial development process, which is calibrated to the observed increase in measures of financial intermediation along the growth experiences in Section 1.

To match the external finance to GDP ratio in the pre-reform period, we begin with $\lambda=1$.13. In year 0 , we maintain the assumption that all idiosyncratic distortions are removed at once. In addition, we assume now that $\lambda$ increases linearly from 1.13 to $1.55-$ where it then stays permanently - over the next 20 years, which implies an increase in the external finance to GDP ratio from 0.3 to 0.86 , which also takes 20 years in the data. We assume that individuals in the model have perfect foresight about this exogenous $\lambda$ process.

We assume that the pre-reform economy is the steady state with $\lambda=1.13$ and also with idiosyncratic distortions. As in the benchmark exercise, we choose the parameters governing idiosyncratic distortions so that measured TFP is higher by one-third and capital-to-output ratio is higher by 37 percent after 20 years of post-reform transitions.
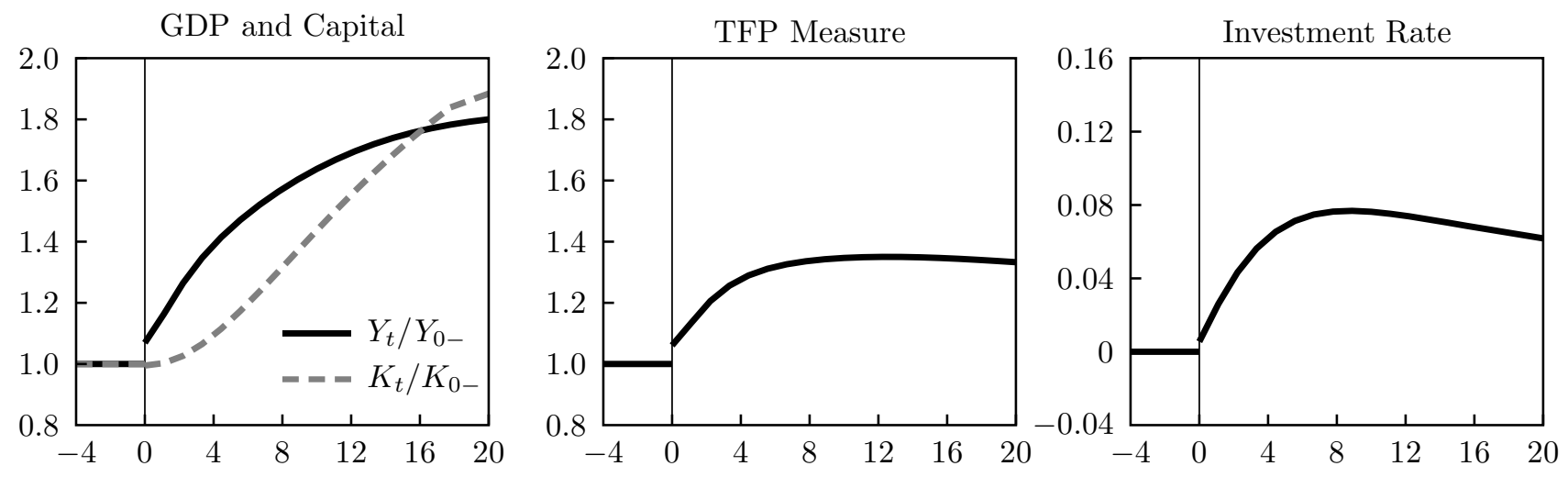

Fig. 7: Transition Dynamics with Gradual Financial Development

The transitions are shown in Figure 7. The results are qualitatively similar to the benchmark results in Section 3.3.1. With a linearly increasing $\lambda$, this exercise has more financial frictions than the benchmark exercise exactly when the economy has the most misallocation (i.e., right after the reform). Not surprisingly, especially immediately following the reform, the reallocation and the transitions are slower here: It takes 13 years (rather than 
10.5) for the aggregate capital to cover half the distance to the new steady state. Investmentto-output ratio also rises more gradually than in the benchmark exercise, as the more severe financial frictions in early stages slow down the growth of talented-but-poor entrepreneurs.

In summary, this exercise makes two points. First, our framework is rich enough that we can accommodate exogenous paths of financial frictions and, similarly, of the reforms that reduce idiosyncratic distortions. Second, the gradual financial development in the data strengthens our quantitative results, as it implies that the financial markets are at their worst precisely when the economy has the most misallocation to be unwound through them.

\subsubsection{Post-Reform Transition with Capital Flows}

So far, we have only considered general equilibrium models of economic transitions. Financial frictions limit entrepreneurs' external sources of capital, and give such constrained entrepreneurs an extra reason to save: self-financing. As we show in Section 3.2, the effects on the demand and supply in the capital rental market drive the equilibrium interest rate down.

If one assumes that the world interest rate is determined by a large country with fully developed financial markets (i.e., perfect credit markets), this rate is - at 4.5 percent per year-much higher than the interest rates of the benchmark transition (Figure 4). If an economy in transition were to open up to capital flows, then capital will flow out of it. Here, we study the impact of the higher interest rate and the resulting capital outflows on the post-reform transition dynamics, by executing the benchmark exercise for a small open economy. $^{22}$

We assume that the initial condition is the same as in the benchmark exercise. Thus, the economy can be thought of as being closed prior to year 0 . In year 0 , a reform eliminates all idiosyncratic distortions, and liberalizes capital flows at the same time, taking as given the prevailing world interest rate. As in the benchmark exercise, we assume that local financial frictions remain as before $(\lambda=1.35)$ through the transition. We are assuming that labor is not mobile across countries.

The results are shown in Figure 8. The most important implication for the open economy transition is that capital flows out: At the new, high interest rate, domestic entrepreneurs' demand for capital falls far short of domestic residents' asset holdings (i.e., supply of capital), and the excess capital goes overseas. In fact, the capital used for domestic production is smaller here than in the benchmark closed-economy exercise, both during the transition and in the new steady state, primarily because of the higher capital rental rate. On the

\footnotetext{
${ }^{22}$ This subsection draws upon a related paper of ours (Buera and Shin, 2010), in which we study the interaction between local financial market frictions and the barriers to international capital flows.
} 

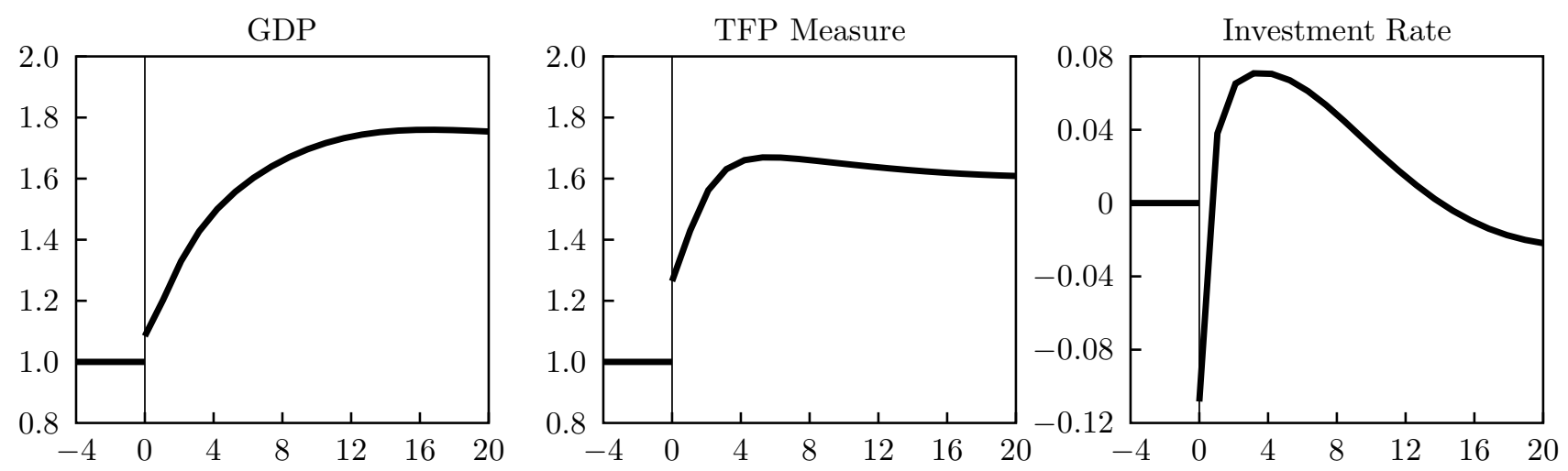

Fig. 8: Transition Dynamics of a Small-Opening Economy

other hand, TFP is higher in the open-economy case than in the closed-economy benchmark. There are two reasons. First, the higher capital rental rate, holding other things equal, makes entrepreneurship less profitable. This drives out entrepreneurs with marginal productivity. Second, the higher interest rate allows the poor-but-talented entrepreneurs to save up faster, as they receive more interest income. Both forces imply better allocation of entrepreneurial talents into active entrepreneurship, which is then reflected on aggregate productivity measures. Overall, it happens that domestic output (i.e., GDP) is lower here than in the closed-economy transition. Note however that domestic residents earn interest income on their foreign assets, which is repatriated in the form of imported consumption goods.

\subsubsection{A Summary of Transition Dynamics}

The rich transition dynamics observed during many growth experiences cannot be explained by the standard neoclassical model. In our framework, we account for these dynamics as a process of unwinding resource misallocation, whose pace is determined by the financial market.

Through the various exercises, we have shown that two ingredients are responsible for the rich transition dynamics. First, there must exist some misallocation to be unwound over time. Second, such reallocation must be intermediated through a financial market that is not perfect. In the benchmark exercise of Section 3.3.1, the removal of idiosyncratic distortions in year 0 constitutes the former, and the tight collateral constraint of $\lambda=1.35$ embodies the latter. As a result, we obtain rich, endogenous transition dynamics that are similar to those observed in the data.

We have also considered a similar reform exercise with perfect credit markets. When the reform removes idiosyncratic distortions, nothing slows down the reallocation process, 
and hence the misallocation is instantaneously resolved. The economy is isomorphic to the standard neoclassical model, and so are the resulting transition dynamics.

In the exercise in Section 3.3.2, there is no more misallocation initially than during or after the transition. Although there are tight financial frictions throughout the transition, in the absence of meaningful reallocation of resources to be done, the transition dynamics are qualitatively and quantitatively similar to the standard neoclassical dynamics.

In Section 3.3.3, we have shown that the model can incorporate exogenous dynamics of gradual financial development (and/or gradual reduction of idiosyncratic distortions) to better match the observed transitional dynamics.

\section{Evidence in Micro-Level Data}

Our model provides a simple, quantitative framework for understanding the transitional dynamics of economies undergoing large-scale, growth-enhancing reforms. At the same time, the microeconomic heterogeneity in our model gives rise to many micro-level implications that the standard neoclassical model with a representative firm is silent about. In this section, we discuss some of these salient implications and confront them with available data.

In the pre-reform economy with its idiosyncratic distortions, productive entrepreneurs are more likely to be taxed, and hence control a smaller fraction of the aggregate capital and labor than is warranted by their productivity. Following a reform that removes such distortions, productive entrepreneurs accumulate collateral (wealth) over time, with capital and labor being reallocated towards more productive plants both at the extensive and the intensive margins (Figure 5). As a result, the degree of resource misallocation diminishes, and the aggregate TFP rises.

One inherent feature of this reallocation process in our model is that the average establishment size — measured by employees per establishment-will increase. One effect of the idiosyncratic distortions is to blur or break the positive correlation between entrepreneurial productivity and establishment size. The reallocation of resources at extensive and intensive margins towards productive entrepreneurs, whose scale of operation when financially unconstrained is larger than that of less productive entrepreneurs, entails an increase in the average establishment size.

We now present evidence that supports our model in these dimensions. First, we show that in all of the reform episodes in Section 1 there is substantial and persistent reallocation of production factors, both across different industrial sectors and from state-owned plants to private-sector ones. Second, we document a persistent rise in the average establishment size in the years following the reforms. Finally, we discuss available direct measurements 
of idiosyncratic distortions and their evolution for China - one of our reform episodes - and India.

Reallocation after Reforms As we describe in the appendix, one salient theme of all the reform episodes is the dismantling of import substitution regimes, i.e., tariffs and subsidies protecting relatively inefficient sectors. More broadly, the reforms were market-oriented, in the sense that they involved a substantial retrenchment of the government's intervention in the economy.

We now present evidence at a disaggregate level that reflects the quantitative importance of these dramatic policy changes. In particular, one can expect to see some quantitative evidence of resource reallocation from entrepreneurs in previously-protected industries to those in export-oriented sectors, and also from state-owned enterprises to private-sector ones. First, in the absence of more disaggregate data on plant-level factor reallocation, we construct and report measures of the reallocation of labor across (2-digit) manufacturing sectors using all available data. Second, we show the sharp rise of private-sector enterprises in the years following the two reform episodes that have relevant data.

We use the UNIDO data on the employment share of 2-digit manufacturing sectors. We also draw upon the data from the national statistics agencies of Japan and Taiwan for the early years not covered by UNIDO. ${ }^{23}$ We compute the gross reallocation of labor across 2-digit manufacturing sectors by summing up the absolute values of the year-to-year changes in each industry's employment share. In the left panel of Figure 9, we show this labor reallocation measure of the six countries normalized by the respective long-run average (average over years 20 through 40 after each reform). The gray solid line is the unweighted average across the six countries. The reallocation measures are highest around the reform date, between 1.5 and 3 times their long-run values, with the cross-section average being double its long-run value. The measures then decline over time: Roughly 8 years after the reform, the average measure is down to 1.5 times its long-run value. ${ }^{24}$

For comparison, we also report a measure of labor reallocation in our benchmark transition exercise (Section 3.3.1). Obviously, our model is a one-sector model, and we cannot construct the exact same sectoral reallocation measure. Instead, we compute the reallocation of labor across plants year-to-year. Essentially, we are using an even more disaggregate data to construct a measure of labor reallocation in the model economy following the large-scale

\footnotetext{
${ }^{23}$ For Thailand, there are no annual data that allow us to construct our labor reallocation measure.

${ }^{24}$ The long-run average of our gross labor reallocation measure is 5 percent, when averaged across the six countries. This is much larger than that of the US: Over the post-ward periods, our gross labor reallocation measure for the US is 2.4 percent on average, with a standard deviation of 1.0 percent. For the US, there is no clear time trend, although our measures are highest, unsurprisingly, right after the second world war.
} 
reform that abolished idiosyncratic distortions. Our labor reallocation measure in the model is normalized by its value in the new steady state, and is depicted with the black solid line in the left panel of Figure 9. In our benchmark transition, our labor reallocation measure during the first 6 years after the reform is quite high, starting from 4 times its long-run value. While not directly comparable, the labor reallocation measures in the data and in the model affirm that the mechanisms in our theory can capture the substantial reallocation of production factors across production units following large-scale policy changes and reforms.

As discussed above, the actual reforms required that the government be less interventionist. Following the reforms, the government's control of the production activities diminished, with a matching rise of the private-sector enterprises. The relevant data are only available for China and Taiwan, and shown in the center panel of Figure 9. On the horizontal axis, year 0 is the reform date for both countries. In both cases, the growth of the private sector accelerates after the reform, with a particularly sharp break for China. Within 10 years of the reform, the fraction of Taiwanese GDP accounted for by private enterprises rises from 50 to 75 percent. $^{25}$ In China, within the same horizon, the fraction of employment accounted for by private enterprises rises from less than 10 percent to more than 40 percent.

In summary, consistent with the underlying mechanism of our model, the reform episodes we identify in Section 1 had an important impact on these economies, not only in terms of the aggregate measures (e.g., GDP and TFP), but also in terms of the measures designed to capture economic changes at a more disaggregate level.
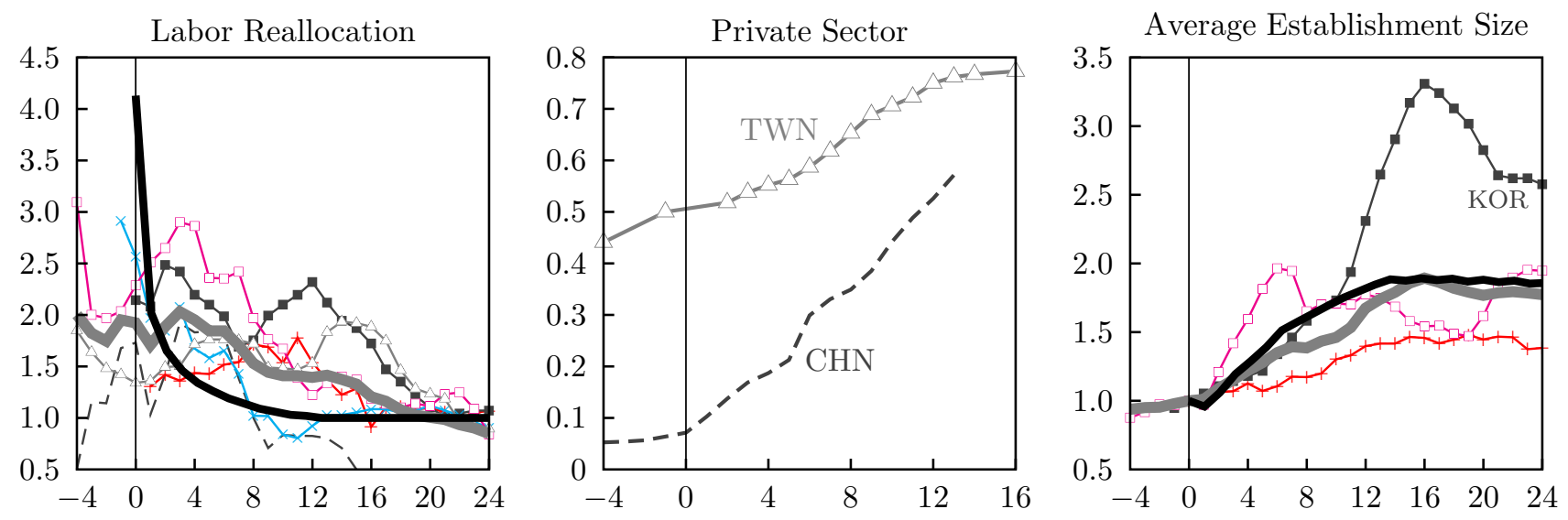

Fig. 9: Micro-Level Evidence

Evolution of Average Establishment Size Another piece of evidence that supports the mechanisms emphasized in our theory pertains to the evolution of the establishment

\footnotetext{
${ }^{25} \mathrm{Schmitz}(1996)$ shows that the rise of private enterprises is observed in all industrial sectors.
} 
size distribution after reforms. For data availability considerations, we define an establishment's size as the number of its employees. In our model, the unconstrained maximal-profit scale of an establishment is positively correlated with the operating entrepreneur's ability. If the pre-reform distribution of wealth and entrepreneurial ability is characterize by substantial misallocation between them, then immediately following the reform, productive entrepreneurs will be financially constrained and hence operate small plants or none at all. Those who are wealthy and unconstrained tend to be not as talented (a statement of the existing ability-wealth misallocation), and choose to operate commensurately small establishments. Over time, as productive entrepreneurs accumulate collateral and overcome the financing constraints (cf. Figure 5), they will operate larger establishments, driving up the average establishment size.

In the right panel of Figure 9, we affirm this intuition by showing the post-reform dynamics of the average establishment size in our model (black solid line, normalized by the pre-reform average establishment size). After a brief drop, the average establishment size increases by 80 percent over the 14 years following the reform, reflecting the reallocation of production factors to the most productive entrepreneurs.

The right panel of Figure 9 also shows the time series of the average manufacturing plant size in Japan, Korea, and Singapore, relative to the size in the respective reform year. ${ }^{26}$ Consistent with our model implications, the average manufacturing plant size increased after the reform in all three countries. On average (gray solid line), plant size increased by 80 percent over the 15 years following the reform, strikingly in line with the model prediction although we did not use this information in our calibration. ${ }^{27}$

A similar pattern emerges in Thailand, where data on employment by firm size bins are available. While the data are available only from 1988, five years after the identified reform, they show a substantial increase in the fraction of workers employed in firms with more than 100 employees (from 21 percent in 1988 to 41 percent in 1998), and also a corresponding decline in the fraction of workers employed in firms with fewer than 10 employees (from 58 percent to 39 percent).

In summary, our model of macroeconomic transitions has a strong implication on the evolution of the average scale of production units, which is supported by all available data. This is a dimension about which the standard neoclassical model with a representative firm

\footnotetext{
${ }^{26}$ We normalize the data by their reform year values to address the fact that the set of plants over which the average size is calculated varies among these countries. The Japanese data cover all plants with more than 4 employees, except for between 1963 and 1977, when they include all plants. We spline the Japanese series to compensate for the discrepancy in coverage. The Korean data include plants with more than or equal to 5 employees. For Singapore, plants employing 10 or more workers are included.

${ }^{27}$ The "over-shooting" in the Korean data around year 16 coincides with its heavy and chemical industry drive of the late 1970s, which was eventually abandoned.
} 
has nothing to say. The rich microeconomic heterogeneity of our model allows us to address these patterns in data, and, more important, helps us better understand macroeconomic transitions.

Reduced-Form Measures of Distortions Finally, we discuss some direct evidence on idiosyncratic distortions that has been made available very recently. To measure establishmentlevel distortions, one needs detailed micro data. There exist few such data sets, and not all of them are readily accessible or reliable. Hsieh and Klenow (2009) use the manufacturing census data of China and India and compute plant-level distortions based on value-added and inputs. ${ }^{28}$ Note that their measure will capture both purely idiosyncratic distortions (e.g., idiosyncratic taxes/subsidies, $\tau_{y i}$ ) and systematic distortions in the economy (e.g., financial frictions, $\lambda)$.

Hsieh and Klenow find substantially more plant-level distortions (and the implied resource misallocation) in China and India than in the US. To give a sense of the impact of the misallocation, they hypothetically reallocate capital and labor to equalize marginal products to the extent observed in the US, and find manufacturing TFP gains of 30-60 percent. ${ }^{29}$ Their findings provide qualitative support for our modeling choice of idiosyncratic distortions and financial frictions: Our benchmark miracle economy has substantially more micro-level distortions both before (because of idiosyncratic distortions and financial frictions) and after (because of financial frictions) the transitions than the perfect-credit economy modeled after the US, although the degree of distortions and misallocation in the benchmark economy decreases substantially after the reform.

The data they use, however, cannot directly answer whether there are significant differences in measured plant-level distortions before and after large-scale reforms. The Chinese data are for 1998, 2001, and 2005, while our reform year for China is 1992: That is, their observation begins 6 years after the reform. Nevertheless, they do report a decrease in the dispersion of marginal productivity - the degree of plant-level distortions - over time in the Chinese manufacturing sector. For example, the difference in marginal productivity between a plant in the 90th percentile and one in the 10th percentile declines by 28 log points by 2005. This reduction in plant-level distortions and misallocation is reflected in the aggregate TFP, and Hsieh and Klenow compute that this channel explains about 2 percent per year growth in measured TFP. This finding is consistent with our model where even the effects

\footnotetext{
${ }^{28}$ Their measure of a plant's wedge or distortions is the geometric average of its marginal revenue products of capital and labor, de-meaned by the average of this quantity across all plants within the same (narrowlydefined) industrial sector.

${ }^{29}$ In this context, we find reasonable our target moment in Section 3.1.2, the 33-percent long-run TFP increase from the elimination of idiosyncratic distortions.
} 
of once-and-for-all reforms manifest themselves over a prolonged period because of financial frictions. Also, one can introduce a gradual removal of idiosyncratic distortions into our model and replicate this finding. ${ }^{30}$

For India, the data cover 1987, 1991, and 1994. Note that India is not one of the economies we study in Section 1. While the Indian government delicensed many industries in 1985 and then in 1991, it lifted its size restrictions much more recently and gradually (1997-2005). In this regard, the Indian data that Hsieh and Klenow use are not informative about the evolution of idiosyncratic distortions following large-scale reforms. Again, one can introduce a sequence of small reforms (i.e., pushing $\tau_{y i}$ 's towards 0 piecemeal over time) into our model to explain the reform and growth experiences of India.

The measurement exercises are useful because they give a sense of the magnitude of the distortions and resource misallocation in the economy. However, by themselves, they are silent about the underlying policies or other causes responsible for the misallocation and also about the particular reforms that reduced them over time. ${ }^{31}$ We supplement these reducedform measurements with a detailed review of historical accounts of the reform episodes in the appendix, paying particular attention to actual changes in specific policies.

\section{Concluding Remarks}

We have incorporated financial frictions and heterogeneous producers into an otherwisestandard neoclassical growth model, and quantified the role of financial frictions and resource misallocation in economic development. We find that financial frictions have a large impact along the transition to the steady state, prolonging the adverse consequences of the initial misallocaiton of resources - hence the sub-title "the persistence of history". Our model economy converges slowly to the steady state, with investment rates and TFP starting low and rising over time. These are all salient features of the growth miracles.

More broadly, our quantitative framework can be applied to the study of macroeconomic transition dynamics following major events or aggregate shocks that jolt an economy out of its status quo.

The post-communist transitions are a relevant example, given the rampant resource misallocation during the communist era and the abrupt liberalizations that followed. The transition paths of various Eastern European countries show diverse patterns, which in

\footnotetext{
${ }^{30}$ See Bartelsman et al. (2009) for a study of the role of idiosyncratic distortions in the US, Western Europe, and the transition economies of Eastern Europe. They find evidence that in the Eastern European economies idiosyncratic distortions diminished along the transition.

${ }^{31}$ Hsieh and Klenow indicate that some of the distortions can be traced to state ownership of plants (China) and licensing and size restrictions (India).
} 
our framework can be quantitatively explained by the differences in their degree of initial misallocation, in the depth, breadth, and pace of their reforms and liberalizations, and also in the degree of local financial market frictions.

Another, perhaps more readily relatable to our exercise, is the recent growth acceleration of Vietnam. Its growth path after the large-scale reforms of 1989 shares many features with our 7 miracle episodes, both at the aggregate and at the micro level. The reforms drastically curtailed the government's intervention in the economy and promoted the private sector. However, the financial markets in Vietnam largely remain underdeveloped up to this day. As a result, we observe a sustained period of massive resource reallocation across sectors and also from state-owned to private enterprises, which also coincided with gradual increases in the average size of establishments and in aggregate investment rates and TFP.

Our model generates transition dynamics that are substantially slower than the standard neoclassical dynamics. However, the model transition is not slow enough, when compared with the data from the growth acceleration episodes. The TFP dynamics in the data appear particularly protracted. One explanation is that the large-scale reforms were cumulative and implemented gradually over several years, as is suggested by our review of the reform history. One can incorporate gradual reforms into our framework in a straightforward manner to further slow down the model transitions. However, the challenge will then be whether one can quantitatively discipline the time paths of the reforms, in the absence of direct, quantified measures of policy distortions. 


\section{A Appendix on Historical Accounts of Reform Episodes}

In this appendix, we expand on our discussion in Section 1 and describe the reforms that preceded the growth accelerations in the 7 economies. In each case, we select as our reform date the year in which the major reforms were announced: China, 1992; Japan, 1949; Korea, 1961; Malaysia, 1968; Singapore, 1967; Taiwan, 1959; and Thailand, 1983. In reality, these reforms were unfolded over a few years, and therefore different years could have been selected. The empirical facts highlighted in Section 1 are robust to such considerations. ${ }^{32}$

China After a decade in which reforms were primarily focused on the agricultural sector and rural areas, the second phase of farther-reaching reforms was inaugurated in 1992, when the Chinese Communist Party endorsed the "socialist market economy" as the guiding principle of China's economic reform. These reforms espoused a more unrestricted growth of private enterprises, going beyond rural township and village enterprises and those in special development zones. They also expanded and further liberalized special development zones, and eliminated price controls. During the 1990s, China pressed on with trade liberalization, and eventually reached a free-trade agreement with the US in 1999 and joined the World Trade Organization in 2001. (Chow, 2007; Qian, 2000)

Japan The immediate post-war period was characterized by the government's direct control of the economy (priority production system) under the tutelage of the occupation authority. These policies were broadly based upon the economic arrangements that had prevailed in the pre-war period. Factor markets, production, and foreign trade were all directly controlled by the government through explicit targets and subsidies. In 1949, under the US influence, Japan introduced a drastic fiscal adjustment program, which included the elimination of subsidies and price controls and the restoration of private channels of international trade that bypassed government agencies. The role of the government shifted from directing production to promoting more efficient technologies (industrial rationalization plans) and export through tax and credit advantages. (Johnson, 1982; Kosai, 1988)

Korea In the first eight years after the Korean War, Korea relied on an import-substitution development strategy. In this period, the economy depended heavily on foreign aid, and was characterized by large fiscal deficits, high inflation, and anemic economic growth. In 1961, a new political regime came to power through a military coup, and embarked on a period of aggressive export promotion that replaced previous inward-looking import substitution policies. This was mainly achieved by combining a free trade regime for exporters, who were now allowed to import freely intermediate inputs and equipment, with high tariffs for final goods. This phase was followed by a burst of more interventionist policies in the late 1970s (heavy and chemical industry promotion). From 1982 on, Korea pursued broader

\footnotetext{
${ }^{32}$ Examples of sensible alternatives are: 1953 for Japan, when it regained full sovereignty; 1971 for Malaysia, when the New Economic Policy provided further incentives to exporters; 1981 for Thailand, when the government started to gradually adopt export promotion policies.
} 
liberalization of trade and capital flows, and a reversal of the credit and tax incentives for large industrial groups. (Hong, 2002; Kim and Leipziger, 1997; Stern et al., 1995)

Malaysia In the first decade following independence, the Malaysian government intervened extensively in the economy to promote rural development, and implemented an importsubstitution development strategy. The Investment Incentives Act of 1968 signaled a shift away from import substitution into export promotion. The Malaysian government accelerated the shift with the New Economic Policy of 1971. Export incentives were given to new industries, mainly through the designation of export processing zones and free trade zones. After the brief and unsuccessful state-sponsored heavy industry promotion in the early 1980s, the 1985-86 recession triggered a second round of market liberalizations aimed at private sector growth. (Salleh and Meyananthan, 1997)

Singapore During the decade leading to its formal independence in 1965, Singapore pursued import-substitution policies, with housing development and construction playing an important role. In 1967, following the failed attempt at integrating with Malaysia (19631965), the government had to abandon import substitution as a growth strategy for a city state with no natural resources. At that point, the government switched its investment promotion efforts toward export-oriented manufacturing. Direct incentives to exporters included concessionary tax rates on export profits. Trade was continuously liberalized, and by 1973 all quotas and almost all import tariffs were eliminated. (Soon and Tan, 1997)

Taiwan The first decade following the retreat from mainland China witnessed a pervasive intervention of the government in the economy. The state controlled half of the industrial production, and its trade policies discouraged imports and exports (e.g., dual exchange rate regime). In 1959, Taiwan drafted and implemented the Nineteen-Point Program of Economic and Financial Reform. Its central objectives were to promote private-sector investment and to gradually diminish the role of the government in industrial production and trade. Import licensing system was dismantled and tax advantages were granted to exporters. In the late 1970s, Taiwan briefly reverted to import substitution policies, promoting the capital-intensive heavy and petrochemical industries. These new import substitution policies prevailed until 1982. Since then, the government has broadly liberalized the economy and pursued marketoriented policies. (Dahlman and Sananikone, 1997; Ranis, 1979; Scott, 1979)

Thailand Until the early 1980s, Thailand subscribed to inward-looking policies, favoring consumer goods industries and capital-intensive industries over the agricultural sector (e.g., high tariffs and export taxes on rice). In 1981, the government began to institute policies promoting export. Export taxes were reduced, and exchange rate controls were eased. At the same time, an effort to rationalize tariffs was initiated. Starting in 1983, the bias in favor of capital-intensive industries was removed, and export projects were given priority through credit and tax advantages. The government streamlined customs procedures and abolished unnecessary regulations, expediting the export process. Trade liberalization continued through the late 1980s and early 1990s. Furthermore, Thailand undertook extensive 
domestic financial market liberalization and capital account liberalization in the late 1980s. (Christensen et al., 1997; Townsend, 2010)

\section{B Appendix on Numerical Algorithm}

\section{B.1 Computing the stationary equilibrium}

We solve for the stationary equilibrium of this economy based on the nested fixed-point algorithm of Aiyagari (1994). The difference is that we have to iterate on both wage $w$ and interest rate $r$ until both labor and capital markets clear in the stationary equilibrium. We start by fixing a $T$, the period by which the economy must have reached the steady state. We choose $T$ to be 200 years. We numerically verify that increasing $T$ to 300 has virtually no effect on the invariant distribution.

1. Guess the interest rate in the invariant distribution, $r^{i}$.

2. Guess the wage in the invariant distribution, $w^{i, j}$.

3. Given the guesses on interest rate and wage, solve the individuals' problem in the stationary equilibrium. Given the optimal decision rule, simulate $N$ individuals for $T$ periods. We set $N=350,000$.

4. Check the labor market clearing condition in period $T$. If there is excess labor demand (supply), choose a new wage $w^{i, j+1}$ that is greater (smaller) than $w^{i, j}$.

5. Repeat Steps 3-4 until the labor market clears in period $T$.

6. Check the capital market clearing condition in period $T$. If there is excess capital demand (supply), choose a new interest rate $r^{i+1}$ that is greater (smaller) than $r^{i}$.

7. Repeat Steps 2-6 until the capital market also clears in period $T$.

\section{B.2 Computing the transition dynamics}

To compute the entire transition dynamics, we have to iterate on the wage and interest rate sequences. Taking the wage and interest rate sequences as given, we solve for the individuals' problem-Problem (2), and then check whether labor and capital markets clear for all periods. We fix $T$ at 125 . We numerically verify that increasing $T$ to 150 has no effect on the transition dynamics.

1. Guess at an interest rate sequence $\left\{r_{t}^{i}\right\}_{t=0}^{T}$.

2. Guess a wage sequence $\left\{w_{t}^{i, j}\right\}_{t=0}^{T}$. Compute the value function of the stationary equilibrium, and let $v_{T}(a ; e)=v(a ; e)$. By backward induction, taking the wage sequence $\left\{w_{t}^{i, j}\right\}_{t=0}^{T}$ and the interest rate sequence $\left\{r_{t}^{i}\right\}_{t=0}^{T}$ as given, compute the value function $v_{t}(a ; e)$ for $t=T-1, \ldots, 0$. Using the optimal decision rule, simulate $N$ individuals for $T$ periods. We again set $N=350,000$. Check whether the labor market clears in every period. Taking the individuals' capital holdings as given, construct a sequence $\left\{\varpi_{t}^{i, j}\right\}_{t=0}^{T}$ that clears the labor market for each period. Update the wage sequence: $w_{t}^{i, j+1}=\eta_{w} \varpi_{t}^{i, j}+\left(1-\eta_{w}\right) w_{t}^{i, j}, \forall t$, with $\eta_{w} \in(0,1)$. Iterate on the wage sequence until convergence. 
3. Once the wage sequence converges, check whether the capital market clears in all periods. Taking the individuals' capital holdings as given, construct a sequence $\left\{\iota_{t}\right\}_{t=0}^{T}$ that clears the static capital rental market for each period. The updated interest rate sequence now will be $\eta_{r} \iota_{t}+\left(1-\eta_{r}\right) r_{t}^{i}, \forall t$, with $\eta_{r} \in(0,1)$.

4. Repeat Steps 2-3 until the interest rate sequence also converges.

As we cannot guarantee the uniqueness of a numerically-constructed competitive equilibrium, we tried many different initial guesses of the wage and interest rate sequences, as well as several values of the relaxation parameters $\left(\eta_{w}, \eta_{r}\right)$. All our competitive equilibria withstood these robustness checks. 


\section{References}

Aiyagari, S. R. (1994): "Uninsured Idiosyncratic Risk and Aggregate Saving," Quarterly Journal of Economics, 109, 659-684.

Atkeson, A. And P. J. Kehoe (1997): "Industry Evolution and Transition: A Neoclassical Benchmark," Working paper, National Bureau of Economic Research.

Banerjee, A. V. And E. Duflo (2005): "Growth Theory through the Lens of Development Economics," in Handbook of Economic Growth, ed. by P. Aghion and S. N. Durlauf, Amsterdam: Elsevier, vol. 1A, 473-552.

Bartelsman, E. J., J. Haltiwanger, and S. Scarpetta (2009): "Cross Country Differences in Productivity: The Role of Allocation and Selection," Working Paper 15490, National Bureau of Economic Research.

Beck, T., A. DemirgüÇ-Kunt, And R. Levine (2000): "A New Database on the Structure and Development of the Financial Sector," World Bank Economic Review, 14, 597-605.

Bernanke, B. S. And R. S. Gürkaynak (2001): "Is Growth Exogenous? Taking Mankiw, Romer and Weil Seriously," in NBER Macroeconomics Annual, ed. by B. S. Bernanke and K. Rogoff, Cambridge, MA: MIT Press, 11-57.

Blanchard, O. J. (1997): The Economics of Post-Communist Transition, Oxford: Clarendon Press.

Buera, F. J. And Y. Shin (2010): "Productivity Growth and Capital Flows: The Dynamics of Reforms," Manuscript, Washington University in St. Louis.

Calvo, G. A. and F. Coricelli (1992): "Stabilizing a Previously Centrally Planned Economy: Poland 1990," Economic Policy, 7, 175-226.

Camdessus, M. (1999): Second Generation Reforms: Reflections and New Challenges, available at http://www.imf.org/external/np/speeches/1999/110899.HTM.

Chen, K., A. İmrohoroĞLu, And S. İmrohoroĞLu (2006): "The Japanese Saving Rate," American Economic Review, 96, 1850-1858.

Chow, G. C. (2007): China's Economic Transformation, Oxford: Blackwell Publishing.

Christensen, S. R., D. Dollar, A. Siamwalla, and P. Vichyanond (1997): "Thailand: The Institutional and Political Underpinnings of Growth," in Lessons from East Asia, ed. by D. M. Leipziger, Ann Arbor: University of Michigan Press, 345-386.

Christiano, L. J. (1989): "Understanding Japan's Saving Rate: The Reconstruction Hypothesis," Federal Reserve Bank of Minneapolis Quarterly Review, 13, 10-25. 
Dahlman, C. J. and O. Sananikone (1997): "Taiwan, China: Policies and Institutions for Rapid Growth," in Lessons from East Asia, ed. by D. M. Leipziger, Ann Arbor: University of Michigan Press, 83-154.

Giné, X. And R. M. Townsend (2004): "Evaluation of Financial Liberalization: A General Equilibrium Model with Constrained Occupation Choice," Journal of Development Economics, 74, 269-307.

Hausmann, R., L. Pritchett, And D. Rodrik (2005): "Growth Accelerations," Journal of Economic Growth, 10, 303-329.

Hong, W. (2002): Catch-up and Crisis in Korea, Cheltenham: Edward Elgar.

Hsien, C.-T. And P. Klenow (2009): "Misallocation and Manufacturing TFP in China and India," Quarterly Journal of Economics, 124, 1403-1448.

Jeong, H. And R. M. Townsend (2007): "Sources of TFP Growth: Occupational Choice and Financial Deepening," Economic Theory, 32, 197-221.

(2008): "Growth and Inequality: Model Evaluation Based on an EstimationCalibration Strategy," Macroeconomic Dynamics, 12, 231-284.

Johnson, C. A. (1982): MITI and the Japanese Miracle: The Growth of Industrial Policy, 1925-1975, Palo Alto: Stanford University Press.

Jones, B. F. And B. A. Olken (2005): "The Anatomy of Start-Stop Growth," Working Paper 11528, National Bureau of Economic Research.

(2008): "The Anatomy of Start-Stop Growth," Review of Economics and Statistics, $90,582-587$.

Kim, K. And D. M. Leipziger (1997): "Korea: A Case of Government-Led Development," in Lessons from East Asia, ed. by D. M. Leipziger, Ann Arbor: University of Michigan Press, $155-212$.

King, R. G. And S. T. Rebelo (1993): "Transitional Dynamics and Economic Growth in the Neoclassical Model," American Economic Review, 83, 908-931.

KosaI, Y. (1988): "The Postwar Japanese Economy, 1945-1973," in The Cambridge History of Japan: The Twentieth Century, ed. by P. Duus, New York: Cambridge University Press, vol. $6,495-544$.

McKinnon, R. I. (1981): "Financial Repression and the Liberalization Problem within Less Developed Countries," in The World Economic Order: Past and Prospects, ed. by S. Grassman and E. Lundberg, New York: St. Martin's Press, 365-386.

Navia, P. and A. Velasco (2003): "The Politics of Second-Generation Reforms," in After the Washington Consensus: Restarting Growth and Reform in Latin America, ed. by P.-P. Kuczynski and J. Williamson, Washington, DC: Peterson Institute, 265-303. 
Ohanian, L. E. And M. L. J. Wright (2008): "Where Did Capital Flow? Fifty Years of International Rate of Return Differentials and Capital Flows," Manuscript, UCLA.

Pritchett, L. (2000): "Understanding Patterns of Economic Growth: Searching for Hills among Plateaus, Mountains,and Plains," The World Bank Economic Review, 14, 221-250.

Qian, Y. (2000): "The Process of China's Market Transition (1978-98): The Evolutionary, Historical, and Comparative Perspectives," Journal of Institutional and Theoretical Economics, 156, 151-171.

RAnis, G. (1979): "Industrial Development," in Economic Growth and Structural Change in Taiwan: The Postwar Experience of the Republic of China, ed. by W. Galenson, Ithaca: Cornell University Press.

Restuccia, D. And R. Rogerson (2008): "Policy Distortions and Aggregate Productivity with Heterogeneous Establishments," Review of Economic Dynamics, 11, 707-720.

Roland, G. (2000): Transition and Economics: Politics, Markets, and Firms, Cambridge: MIT Press.

Sachs, J. D. And A. M. Warner (1995): "Economic Reform and the Process of Global Integration," Brookings Papers on Economic Activity, 1995, 1-118.

Salleh, I. M. And S. D. Meyananthan (1997): "Malaysia: Growth, Equity, and Structural Transformation," in Lessons from East Asia, ed. by D. M. Leipziger, Ann Arbor: University of Michigan Press, 279-344.

Schmitz, J. A. (1996): "The Role Played by Public Enterprises: How Much Does It Differ Across Countries?" Federal Reserve Bank of Minneapolis Quarterly Review, 20, 2-15.

ScotT, M. (1979): "Foreign Trade," in Economic Growth and Structural Change in Taiwan: The Postwar Experience of the Republic of China, ed. by W. Galenson, Ithaca: Cornell University Press.

Soon, T.-W. And C. S. Tan (1997): "Singapore: Public Policy and Economic Development," in Lessons from East Asia, ed. by D. M. Leipziger, Ann Arbor: University of Michigan Press, 213-276.

Stern, J. J., J.-H. Kim, D. H. Perkins, And J.-H. Yoo (1995): Industrialization and the State: The Korean Heavy and Chemical Industry Drive, Cambridge: Harvard Institute for International Development.

Townsend, R. M. (2010): Financial Systems in Developing Economies: Growth, Inequality and Policy Evaluation in Thailand, Oxford: Oxford University Press. 